\title{
AN EXAMINATION OF THE IMPACT OF A TRAINING PROGRAMME BASED ON SPORT PSYCHOLOGY FOR A COHORT OF CONTEMPORARY SINGING STUDENTS
}

BY

SANDY CAIRNS-JAMES

\begin{abstract}
A thesis
submitted to the Victoria University of Wellington in fulfilment of the requirements for the degree of Master of Arts in Education
\end{abstract}

Victoria University of Wellington 2012 


\section{Abstract}

Sport psychology is well recognised and accepted as an important aspect of sports training, especially for elite athletes. Sport psychology focuses on teaching skills and methods such as goal setting and mental preparation for athletes so that they can develop their psychological abilities to the same high level as their physical abilities. Few researchers have linked sports and singing training, but it appears that many of the techniques used in sport psychology could be of value in developing singers' practice and performance skills.

This study examined the overall impact of introducing sport psychologybased training into the curriculum of a cohort of tertiary level contemporary singing students, using a qualitative case study approach. Five categories from sport psychology methods were identified for the purpose of this research: deliberate practice, self-efficacy, motivation, goal setting and peak performance were introduced into the teaching of the singing programme. Analysis of the impact revealed that sport psychology methods were not easily transferable into this vocal curriculum. The outcomes showed that the participants' level of development in terms of learning skills was at a lower level than the demands of sport psychology.

\section{Acknowledgements}

This thesis has been possible owing to the energy and commitment of several individuals who have contributed their valuable knowledge and encouragement throughout the preparation and completion of this project. 
First and foremost, my heart-felt appreciation goes to my supervisor, Dr. Barrie Gordon, whose foresight and intuition gave me the ability to keep trusting and believing in what was possible. Barrie has given me the strength and belief in myself to journey into the academic arena. His calm persona and forthright direction lead me through some challenging times which I am truly grateful. His intuition and professional approach as a supervisor was of a high standard and he is truly a credit to his profession.

I would also like to thank my co-supervisor, Jenny Wollerman, for her support and belief in developing a singing programme that embraced contemporary singers. Her broad knowledge base and professional perceptiveness are worthy of acknowledgement and I know that our association has just began. Without her, this study would not have carried the desired credibility.

I am especially grateful to Dr. Alison Viskovic who faithfully encouraged me throughout my academic venture and also assisted in co-ordinating the participants at the tertiary institution associated with this thesis. Her years of experience, and availability as the support colleague, were invaluable and a stabilizing presence for all of us who were personally involved in the research. I would like to extend my sincere thanks to Kaye Jujnovich, Dean of Faculty of Arts, and all my colleagues for their continued support and encouragement during my academic pursuit. Thank you to Kirsten Reid for her expertise and support.

To my family, I am so thankful for their on-going love and prayers. I thank my husband for his continued love and encouragement throughout this thesis. Finally, I dedicate this thesis to the students participating in this project, without whose consent and valuable insight it would never have happened. Without their personal interaction this project would not have held credibility for contemporary singers. And to the contemporary singers of New Zealand, who I believe deserve the most excellent vocal training, I dedicate 
my academic journey in continuing to pursue excellence and add to the body of knowledge in contemporary voice. Thank you all so much.

\section{TABLE OF CONTENTS}

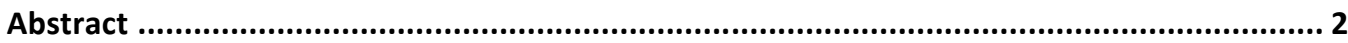

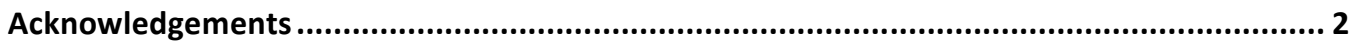

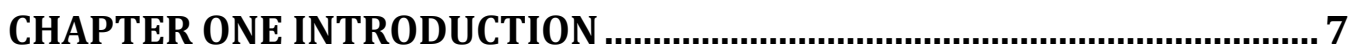

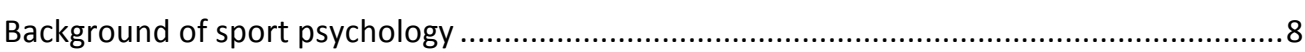

CHAPTER TWO LITERATURE REVIEW ....................................................11

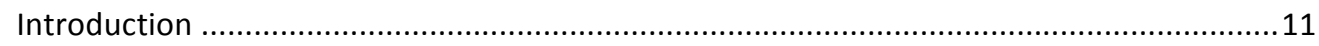

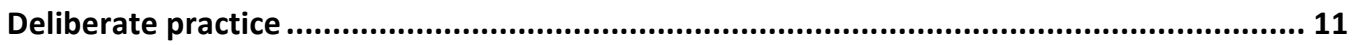

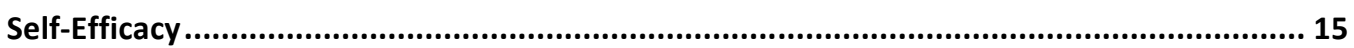

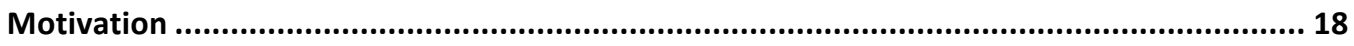

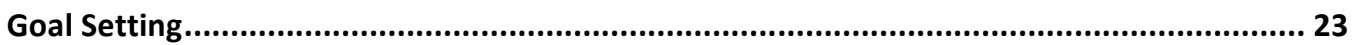

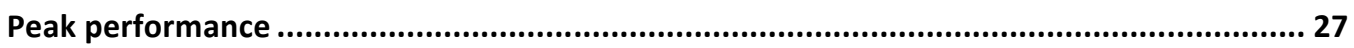

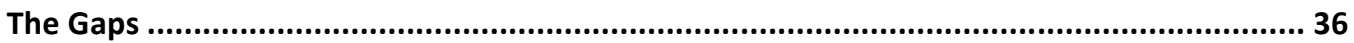

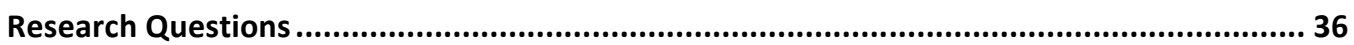

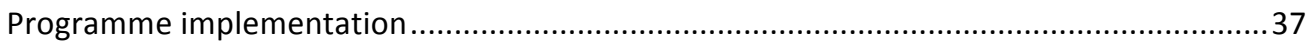

CHAPTER THREE RESEARCH PROCESS _..................................................38

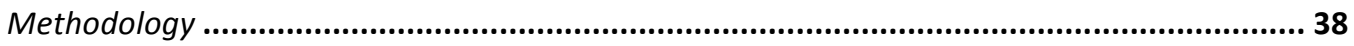

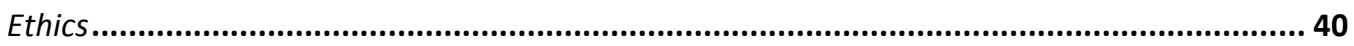

Participants .................................................................................................................. 41 


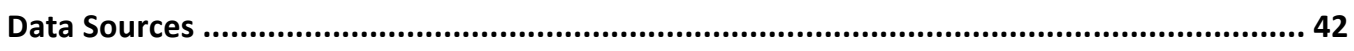

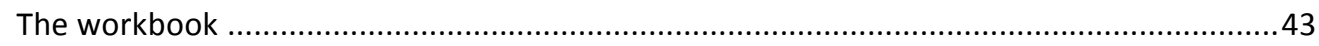

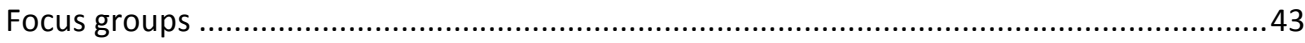

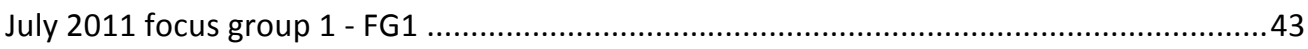

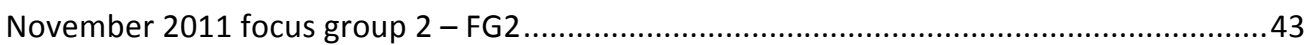

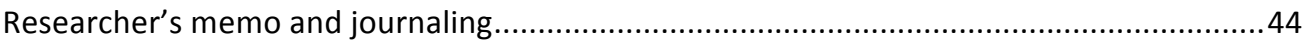

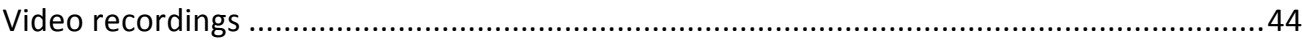

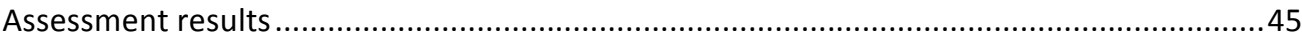

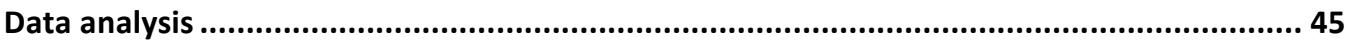

CHAPTER FOUR FINDINGS ..........................................................................47

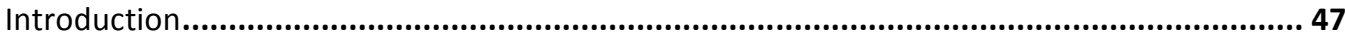

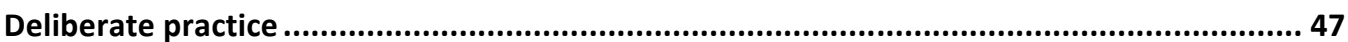

Deliberate practice - the workbook .......................................................................... 47

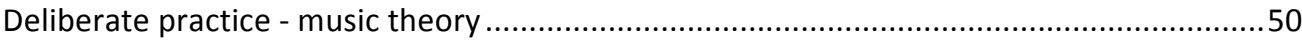

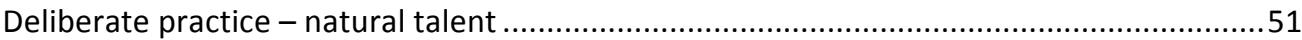

Deliberate practice - the environment ...................................................................... 52

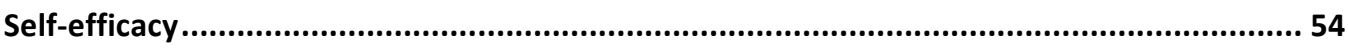

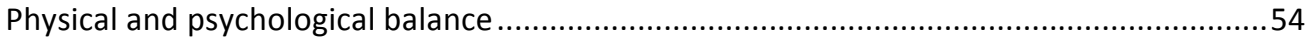

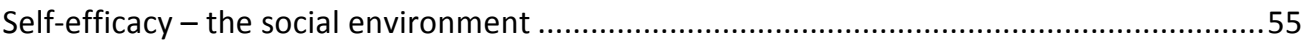

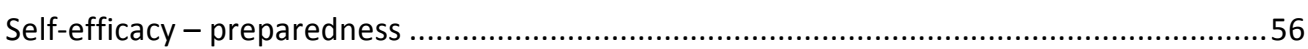

Emergent theme - vocal coach/ singer relationship.......................................................57

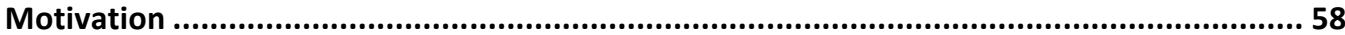

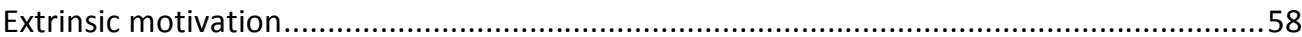

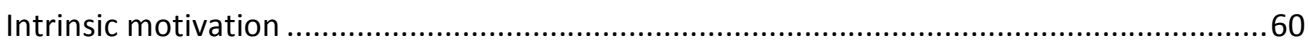

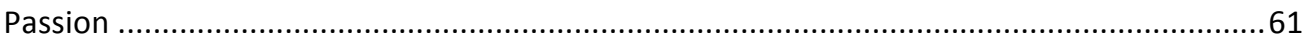

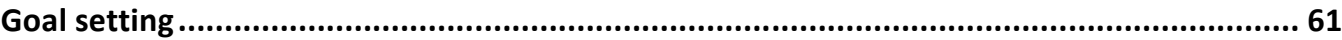

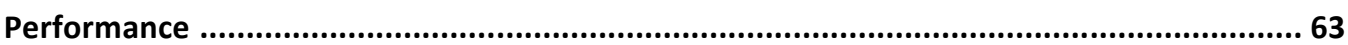

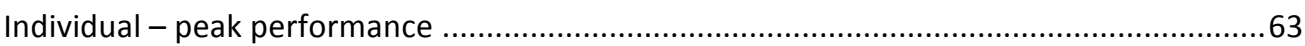

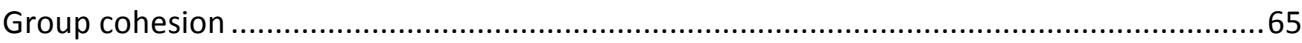

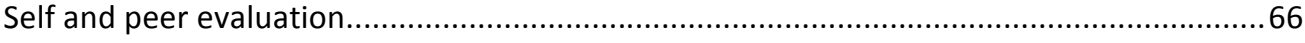

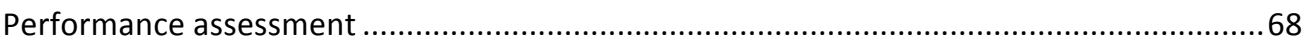




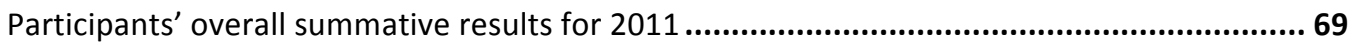

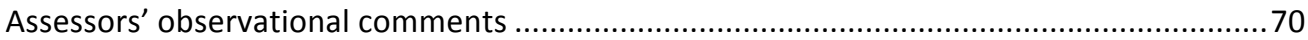

CHAPTER FIVE DISCUSSION AND CONCLUSION.......................................72

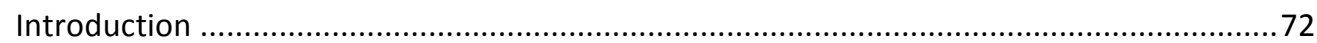

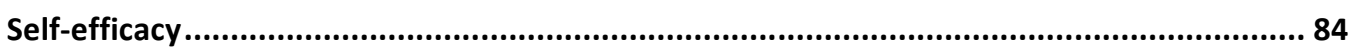

Self- efficacy - physical and psychological balance ......................................................... 84

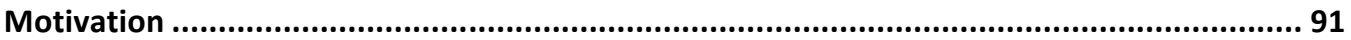

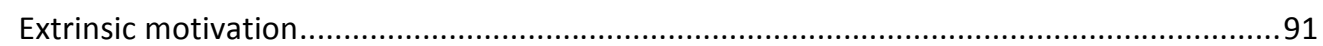

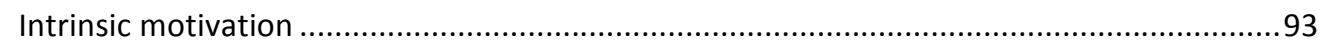

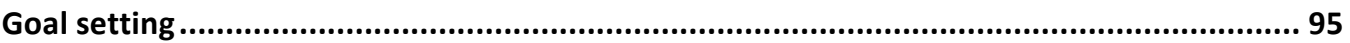

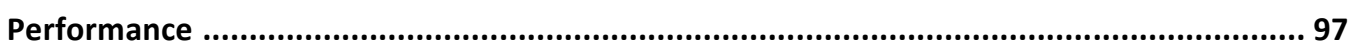

Self and peer evaluation relating to performance .................................................... 100

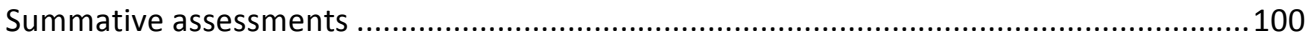

Summary, implications \& Suggestions for Future research ........................................101

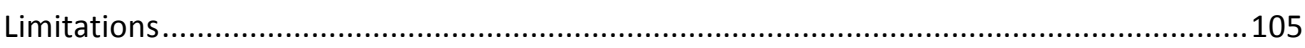

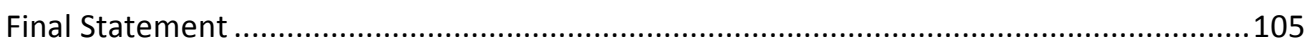

REFERENCE ...........................................................................................106

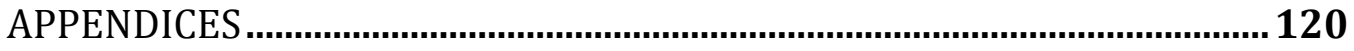

Appendix 1: Information and consent form ............................................................ 120

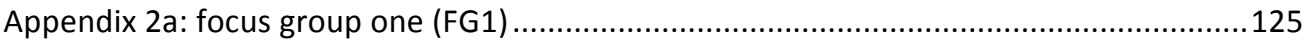

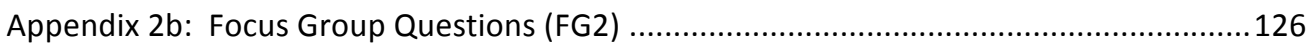

Appendix 2a: Question for assessor and moderator....................................................... 128

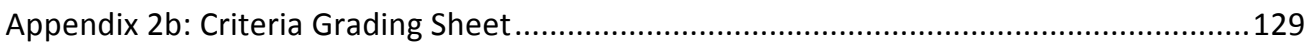

Appendix 3: GPSMAD - memoing technique ......................................................... 130

Appendix 4a - Sample layout of Book one (week one) ..............................................131

Appendix 4b: an example from students deliberate practice workbook ............................136 


\section{CHAPTER ONE INTRODUCTION}

This thesis examines the impact of a training programme, based on the principles of sport psychology, on a cohort of contemporary singing students. More specifically, it seeks to reveal the participants' responses to engaging in sport psychology-based activities and the overall effect this had on performance. This examination will explore the students' actions and experiences over an academic year of voice studies.

The teaching of singing in New Zealand is historically founded in the Western European acoustic vocal tradition including opera, bel canto and lieder. In these traditions, the voice is treated as an acoustic instrument, with vocal timbres and many aspects of interpretation dictated by the music as composed. Musical theatre has also developed its own voice pedagogy that has influenced musical genres including rock, pop and jazz. The emergence of rock, pop, jazz and musical theatre genres has altered the vocal landscape, adding different sounds and stylistic approaches. In more recent years, vocal pedagogy has included these genres in an effort to meet the new vocal demands of a changing professional performance environment (Lebon, 2006).

Although contemporary singing training has consistently developed over the past 25 years, there has been limited research in this area. There are several mixed vocal pedagogy methods used in contemporary training methods, which focus on appropriate vocal technique, but there are few that examine the psychological aspect of vocal training.

One area that has a strong commitment to improve performance through psychology is that of sport. Sport psychology training is common practice in the sports domain for peak performance development. It was therefore 
important to examine sport practices to find inspiration on how to develop peak performance within singing training methodology which was the initial focus of this investigation.

Further investigation is required to expand the body of knowledge that can support and challenge pop, rock and jazz vocal pedagogy independently. This research will focus on aspects of sport psychology methods to see whether these methods maybe beneficial and transferable to contemporary singing training. The following research questions will allow for an examination of whether and how these methods may transfer successfully or create challenges that may not be useful for contemporary singing training.

\section{Research Questions}

\section{What is the impact of a training programme based on sport psychology for a cohort of contemporary singing students?}

Do goal setting, motivation, self-efficacy and deliberate practice have an impact on performance, and if so in what ways?

Do motivation mechanisms increase deliberate practice, and if so in what ways?

In what ways does team flow influence peak performance?

\section{Background of sport psychology}

In 1898, the first article directly associated with sport psychology was published by Norman Triplett. He made the observation that if a cyclist was competing with another cyclist, at the same level of expertise, he was more likely to improve his finishing time than if he rode alone. In the 1920 s Coleman Griffith researched psychomotor skills learning (relating to bodily movement triggered by mental activity, especially voluntary muscle action), 
and personality characteristics, and developed research measures and procedures that he initially applied to American football training. The focus of psychology applied to sport in the early stages appears to have been on psychological testing. In the 1940 s and 1950 s there was a move toward teaching athletes psychological skills to help them improve performance (Kornspan, 2009).

It was not until the 1972 Munich Olympic Games however, that sport psychology was acknowledged and identified as an essential element to empower elite athletes for peak performance. In the 1980s it became increasingly common to hear about successful athletes and coaches working with sport psychologists. This trend has continued and in the current sport culture it is common practice for sports training to be multi-layered and holistic. Elite athletes today are more likely to approach their training holistically so that both physical and psychological abilities are balanced and exhibit the same level of competence (Kornspan, 2009).

In the sport domain, researchers and educators recognise the need for both physical and psychological training to produce excellence in performance. This combination has also been considered in the training of musicians. Don Greene (2001), an athletic coach, was invited to work with professional musicians who were struggling to perform to their potential. Greene introduced elements of sport psychology into the selected musicians' training programmes and found that this produced similar results to those achieved in sport.

A major focus of this research was to find ways to inspire students to improve their preparation for performance. The challenge of getting students to engage in deliberate practice has been a consistent one for the researcher over many years of voice coaching and has contributed to this inquiry. In 2005, at a singers' conference in Wellington, Dr Irene Bartlett from Griffith University, Australia, stated that in the field of science, singing was 
recognised as a sport. This comment sparked a re-think on how to train contemporary singers for performance. Questions that needed to be considered were: what does it take to be a world-class winner and how is it that some individuals' talent drives them to excellence time and time again?

The presentation of this thesis will be guided by five categories identified from within sport psychology. First, deliberate practice, which is associated with progressive training and planning, will be emphasised and the effects evaluated. Second, self-efficacy will be explored to examine the singers' psychological stance and what impact this has on performance achievement. Third, students' motivational levels will be investigated in view of training and performance application and to see whether or not motivational mechanisms impact significantly on performance outcomes. Fourth, goal setting methods will be implemented to establish whether or not progressive training is influenced by these factors. Finally, peak performance and summative assessment results will be analysed, to allow the researcher to see whether sport psychology methods can be successfully transferred to the teaching and training of contemporary singers.

\section{Key words}

Deliberate practice, self-efficacy, music performance, performance achievement, contemporary singer, motivation, goal setting and peak performance 


\section{CHAPTER TWO \\ Literature Review}

\section{Introduction}

This chapter reviews the body of literature that is relevant to the research objectives. Since the main focus of the study is on sport psychology and its transferability to contemporary singing training, it is important to identify and outline the major categories relative to this area of study. The review will also consider empirical studies that have been published to date in the area of sports psychology and performance achievement. Literature addressing sport psychology in various domains including sport, music and education will also be reviewed.

For the purpose of this study five categories have been identified. These are deliberate practice, self-efficacy, motivation, goal setting and peak performance. The review is considered through the division of the five categories previously mentioned.

\section{Deliberate practice}

What is deliberate practice? In Colvin's (2008) view it is practice that has been specifically designed for the purpose of producing excellent performance standards. He considers that deliberate practice engagement in all fields needs to be highly repetitive for high skill proficiency. A key 
component of deliberate practice is frequent constructive feedback and above all an effort on focus and concentration; it is not necessarily fun. Basically, deliberate practice pushes us beyond what we can currently do. This view is supported by Ericsson, Krampe and Tesch-Romer (1993) who believe that deliberate practice requires effort, is not enjoyable, and is specifically designed to improve performance.

According to Ericsson and Lehman (1996) the effects of deliberate practice engagement on performance achievement cannot be underestimated; they state that, "As for expertise, the levels of performance individuals attain after years of experience alone are much lower than those who have adhered to regimens of careful training and practice" (p. 297). Bonnevill-Roussy et al., (2010) acknowledged the challenges in sustaining deliberate practices and stated "that passion towards an activity could be the motivational force that helps people initiate and persevere in deliberate practice of their passionate activity" (2010, p. 126).

Natural talent has also been associated with high level performance. Durand-Bush et al., (2001) claimed that there have been many attempts over the past century to define 'talent'. They suggest the use of the term varies considerably and that its meaning is determined by the particular perspective of the users. Geron (as cited in Durand-Bush et al., 2001) found that the profiles of top-level athletes were not sufficient to accurately predict talent. She emphasized the difference between simply enumerating factors predicting performance and recognizing the components necessary for success in a given sport. In other words, there is a difference between the early qualities required for athletes to become champions and the characteristics of champions.

Howe et al. (1998) challenged the idea that natural talent is required for high-level performance and consider that deliberate practice attains excellence. They suggest that performers become highly successful as a result of environmental factors such as intense training rather than innate 
abilities. Bloom (1985) investigated the concept of nature-nurture in view of natural talent and suggested that, "despite the initial characteristics (or gifts) of the individuals, unless there is a long and intensive process of encouragement, nurturance, education, and training, the individuals will not attain extreme levels of capability in these particular fields" (p. 3). Bloom concluded that, "talent development requires years of commitment to learning and that the amount and quality of support and instruction individuals receive from parents, teachers, or coaches is central to this process" (p. 274).

From the music domain Colvin (2008) interviewed music professionals who found that a high percentage of music educators assumed that music students required a special gift or talent. They believed that individuals are born talented, and that was the main reason for successful performance. Ericsson (2006) also observed professional and amateur singers during singing lessons and found that professional singers had a higher level of concentration and focus. He considered that expert performance resulted from extended, deliberate practice, a belief that differs from previous ideas about the important roles of talent and expertise.

The literature from the sport domain identified deliberate practice as a major component in the achievement of peak performance. Research conducted by Orlick and Partington (1988) suggests that quality practice identifies specific training goals and places emphasise on mental training such as "concentration" and "intensity". They found that for an athlete to achieve peak performance a continuum of increasingly specific goals, in both physical and psychological training, must be maintained. The two main factors associated with elite performance according to Orlick and Partington's model of human excellence were commitment and self-confidence (1988).

Other aspects identified as important for successful deliberate practice were progressive training and the avoidance of ineffective practice. Researchers acknowledge that for deliberate practice to work effectively the individual must use strategic training that continues to advance and challenge 
skill acquisition. The designing of such a programme must meet the needs of the individual and be set at an appropriate level so that the challenge in practice activities matches an individual's ability and also eliminates the possibility of arrested development (Bompa, 1999; Ericsson, 2006; Navin 2011).

Lehmann and Davidson (2006) reviewed deliberate practice acquisition which did not produce progressive results. They concluded that "lack of progress or achievement in spite of reported practice time may ultimately be related to a suboptimal quality of practice" (2006, p. 242). Lehmann and Davidson acknowledge that limiting factors such as "resources, effort and motivation" (2006, p. 239) can have a negative impact on practice quality. Other aspects that can interfere with quality practice identified by Jorgensen (2002) were: (1) starting age, (2) quality of past practice and development and (3) difference in repertoire and practice strategy choice. He recommended that students studying in higher education need to be educated in the area of quality practice. Jorgensen was also concerned that educators may assume students need to design their own practice routines, strategies and times and recommended that such assumptions need to be reassessed and evaluated (2002).

In more recent research, Moore (2010) identified practice application differences between elite athletes and musicians. In Moore's view it was not the amount of time spent practising that was most important, but the time spent playing. Moore believes athletes play to practice, while musicians practice for performance preparation. Moore recommended developing mental performance skills that focus on self-instruction, self-monitoring and the ability to analyse cause and effect. He believes it is an individual's 'courage' that allows them to overcome negative internal and external dialogue. To avoid negative thinking the mind must be trained to acknowledge the primary psychological goal during performance which is to maintain a clear and present focus. To assist athletes and musicians Moore formulated methods on "how to practise". He recommended a 80/20 formula practice 
schedule designed for specific event training. The programme designated 80 per cent of practice to technique and 20 per cent to performance 'mindset' training until the final week of a training schedule, at which time the percentages are reversed. The final week introduces 80 per cent of the training for performance and 20 per cent to technique, allowing the focus of practice to concentrate on performance.

A number of writers have addressed the issue of deliberate practice and its influence on peak performance. It was found that educators can have an unrealistic perspective of students' deliberate practice engagement. They believe teachers often assumed that students were well informed about practice routines and expectations but that the evidence proved otherwise. Educators generally considered practice strategies were discussed with students yet the students were more likely to be less informed than predicted. In view of this assumption educators were directed to provide self-guided systems that direct a developing musician to support efficient and quality practice (Kostka, 2002; Lehmann \& Davidson, 2002, 2006)

\section{Self-Efficacy}

One leading researcher who has greatly influenced the thinking around the conceptual development of self-efficacy and its effect on performance is American psychologist Albert Bandura (1977). Bandura identified self-efficacy as a key component in social cognitive theory and suggested that individuals are primarily motivated by self-belief and self-efficacy. Bandura concluded that the individual who exhibits high self-efficacy is more likely to participate more readily, work harder, persist longer and have fewer adverse emotional reactions when they encounter difficulties, than do those who doubt their capability (1977).

In the sport domain, self-efficacy is recognised as a key factor in performance achievement. Hodge (2004) claims that success for any top- 
level coach or athlete is because of their self-belief. He maintained that confident athletes will produce high standard performances even when they experience self-doubt. However, he cautioned that an over-confident approach will hinder performance achievement (2004). The positive aspects of self-efficacy were also acknowledged by Shepherd (2006) who stated that an athlete's performance was directly related to their levels of self-belief and that high level of self-efficacy was associated with successful performance outcomes. Bandura (1997) considered that low self-confidence also directly affects performance ability.

Skills can be easily over-ruled by self-doubts, so that even highly talented individuals make poor use of their capabilities under circumstances that undermine their beliefs in themselves. By the same token a resilient sense of self-efficacy enables individuals to do extraordinary things by productive use of their skills in the face of overwhelming obstacles. (p. 37)

Self-efficacy was associated not only with performance achievement but also with the level of an individual's preparedness. Loehr (1984) considered the implications of inadequate preparation and remarked on the body-mind link response. He concluded that without complete focus and preparation the athlete would create excessive muscle tension and exhibit poor concentration, which would consequently produce ineffective skill acquirement (1984). DeVenzio (1997) adds that self-efficacy is often connected to an athlete's preparedness for an event: "confidence level mirrors skill level" (DeVenzio, 1997, p. 91). DeVenzio states that the difference between the competent athlete and the elite athlete is measured by their psychosomatic qualities. When an athlete is physically and mentally prepared, a high confidence level carries over which decreases anxiety because the athlete knows that they are prepared, and are confident in their chances for success (1997).

According to Hodge (2004, p. 95) there are four major sources of information that will influence the athlete's level of self-confidence. These are: 
1. Whether or not you have performed successfully in the past (performance accomplishments),

2. Watching other athletes/players perform the skill(s) (modelling or 'imitation'),

3. Having other people tell you that you can perform a skill successfully (verbal persuasion),

4. How you interpret your physical and emotional feelings about an upcoming performance (activation levels).

In Hodge's (2004) view, the greatest influence on one's self-efficacy is performance history. Bong and Clark (1999) also considered performance history created elements of performance anxiety and poor self-efficacy and believed that they were interrelated. They suggested that, unless performance history improves, it is unlikely that the individual will change their self-efficacy standpoint. It was also concluded that previous outstanding performances were more likely to enhance confidence, whereas substandard performances were more likely to undermine self-confidence.

Within the sport and educational domain self-efficacy is closely interlinked with self-concepts. Marsh (1984b) proposed a frame-of-reference model called the big-fish-little-pond effect (BFLPE) to encapsulate external frame-of-reference effects. In this model, Marsh hypothesized that people compare their abilities with the abilities of their peers and use this social comparison impression as one basis for forming their own self-concept. In another words, if an individual feels capable of success in their social environment they are more likely to succeed. Conversely, if the individual is subject to a social environment that endorses a higher ability than the individual's, a negative impact on performance achievement is likely. In the sport domain, Marsh and Peart (1988) suggested that BFLPE might be reduced if the emphasis and feedback were focused on cooperation as opposed to competition. They suggested that individual improvement becomes the measure of success when there is more emphasis on intracompetition (within each athlete) and less on inter-competition (between 
athletes); this information is also closely related to an individual's methods of goal setting, which will be discussed later in this chapter.

Self-efficacy was also associated with the athlete/coach relationship. According to Navin (2011) effective coaching is an athlete-centred approach that prompts the requirements and interests of the individual. It was suggested that a coach should take a holistic view of the person, which facilitates an inter-personal relationship between the coach/athlete. To achieve effectiveness within coaching Navin recommended the following factors:

- A high frequency of feedback

- High levels of detection, correction and reinstruction

- High levels of questioning

- The ability to manage and maintain order in the training and competition environment. (p.21).

Navin and Egan (2011) discussed the raising of self-esteem and the importance of understanding the needs of the individual to ensure an effective working relationship. They believed that training programmes must meet the needs of each individual and therefore individually tailored programmes are necessary. Factors that ought to be considered when individualizing training programmes are age, maturity, ability, skill and preparation (2011).

\section{Motivation}

What is motivation? Early writings by Murray (1938) on defining personalities described achievement motivation as a desire that was needed to excel:

...to accomplish something difficult. To master, manipulate or organize physical objects, human beings, or ideas. To do this as rapidly and as independently as possible. To overcome obstacles and attain a high 
standard. To excel one's self. To rival and surpass others. To increase self-regard by the successful exercise of talent. (p.164)

Most athletes would like to experience greatness, to be successful in their sport. Yet only those who truly desire it and are willing to do all that it takes to achieve their highest possible level of performance become champions. An athlete with a desire to achieve would never ask, "Coach, I want to, but what will it take?" Rather, the athlete with desire would say, "Coach I want to - tell me what I need to do now." The latter comment shows deep desire and passion, the willingness to suffer, sacrifice, and serve on the road to realizing one's full potential (Lynch, 2001, p. 115).

In the sport domain, Hodge (2004) strongly suggests that motivation must come from within - intrinsic motivation - to be effective and meaningful, as extrinsic motivation is unlikely to have a lasting effect. Intrinsic motivation empowers an athlete to succeed more than any other motivational factors. Hodge stated that without high levels of motivation and determination it is unlikely high performance levels would be achievable. He also maintained that motivation is essential to psychological training if consistent success is to be achieved and sustained.

The role of empowerment in motivation has been discussed with Arai (1997) suggesting that being empowered encourages intrinsic motivation. To achieve empowerment an individual must move through different phases, which include: self-awareness, responsibility for learning, taking action and contributing to one's own learning.

Another aspect of motivation is an individual's ambition to succeed. Csikszentmihalyi et al. (1993) claim only a minority of youngsters who show signs of talent respond to the need to increase effort and commitment to develop their talent. Lynch (2001) outlines that not all individuals have what it takes to be champions. He writes that there are many competent athletes who do not see the need to go the distance and are satisfied with a good level 
of performance. Many are content with their level of play and do not consider it necessary to extend themselves to their full potential. Even though they may have the potential to excel they are not prepared to sacrifice or challenge themselves to performance advancement. "They are content to remain in their comfort zone" (p. 116).

Although it has been suggested that intrinsic motivation is the most favourable motivator in the pursuit of excellence, it is also worthwhile considering extrinsic motivational aspects. Moreno et al. (2010) examined the coach/athlete relationship from the sport domain in association with motivation and performance. The findings of this research indicated that an athlete's intrinsic motivation was highly influenced by extrinsic motivation initiated by their coach. The results showed that students who were continually affirmed by the coach - 'that they would improve' - were more likely to succeed than those students who experienced negative or no positive feedback (2010). Becker and Wrisberg (2008) also outlined the importance of feedback, and revealed that a performance is undoubtedly influenced by the feedback given by the coach. This was echoed by Deci and Ryan (2008) who believe affirmative feedback contributes to performance competence and autonomy. They also assert that a well-balanced coach/athlete relationship would focus on self-improvement rather than on defeating others and suggested that this approach would enhance performance consistency.

In sport, it is common for an athlete to be under the guidance of an authority figure - coach or instructor. According to Navin and Egan (2011) over the past decade trends toward coaching have changed from drill and repetition to a more autonomous approach. Recent trends tend to take a more holistic approach to training which encourages the development of both physical and psychological training aspects. Salmela (1996) interviewed 22 expert coaches on the topic of expertise development and discovered one of their main goals was to create an environment that was favourable to improving performance. The coaches maintained that extensive time must be invested in planning and designing training programmes that are progressive 
so that the highest quality of training can occur (1996). Kipp and Amorose (2008) believe the relationship between the coach and athlete is vital to motivation and performance outcomes and suggest that the function of this relationship is linked to perceived and self-determined motivation factors. They also state that coaches need to design strategies to facilitate athletes' self-determined motivation, which promotes greater perseverance, improved concentration and enhanced learning. The athlete who develops strong selfdetermined motivation is also less likely to encounter high levels of anxiety that have the potential to negatively impact on performance outcomes. It was also suggested that when athletes engage in high levels of self-determined motivation they are less likely to quit compared to those who have non-selfdetermined levels of motivation.

Passion orientation was also associated with motivation. Lehman and Gruber (2006) discussed the individual's level of passion and considered that a high level of passion was required toward an activity as demanding as playing a sport or musical instrument, otherwise people would drop out before attaining an expert level of performance.

Passion is defined as an intense preference towards a self-defining occupation that people love, that they consider important, and in which they devote significant amount of time and energy (as cited in (Bonnevill-Roussy, 2010, p. 124).

In Deci and Ryan's view (1985; 2008) passion is a major part of a person's identity and more than just a human expression. According to the SelfDetermination Theory (SDT), human beings can connect so strongly to an activity that it is integrated into one's personality. Vallerand et al. (2003; 2008) suggest two types of passion which connect to human activity; harmonious passion and obsessive passion. Harmonious passion is an autonomous connection that contributes positively into one's self. In contrast, an obsessive passion is a controlled connection where people are controlled by external or internal pressures. This level of control can negatively 
determine the individual's level of engagement in the activity. In other words the activity controls the person's life and creates conflicts with other life domains. Consequently, obsessive passion is associated with less positive outcomes than harmonious passion and sometimes leads to negative consequences. Lynch (2001) also points out the dangers associated with obsessive passion and endorses the importance of maintaining a disciplined balance between training and one's personal life.

Research conducted by Mageau, Vallerand, Charest, et, al. (2009) found that both harmonious and obsessive passion existed among highly skilled musicians and athletes. They sampled 84 musicians and 145 athletes with a mean age of 19.6 and found $99 \%$ of the expert performers were passionate. The findings emphasised that harmoniously passionate performers produced a higher performance level than those who were obsessively passionate. Another contributing aspect for passionate orientation was linked to the social environment. It was suggested that when a social environment encouraged autonomy, it was more likely harmonious passion would be exhibited. Gill (2000) also claimed that a social climate that promotes autonomy empowers the individual to feel as though they have internal control which enhances harmonious passion.

In contrast, Mageau, Vallerand, Charest, et al. (2009) found that the individual's instructional history influenced their passion orientation. The researchers considered that obsessive passion was found amongst those participants who had been pressured and dictated to by authority figures in their formative training. The individuals with obsessive passion placed their activity above their personal life regardless of the emotion and the consequences associated with it. It was concluded that harmonious passion plays a major role in sustaining efforts in reaching expert levels, and conversely obsessive passion is unfavourable and less likely to encourage optimal performance levels. 
In sport training visualisation and imagery were commonly used for the purpose of developing confidence and motivational function. Athletes practise the skill by imagining themselves moving to various positions and seeing themselves play offensive and defensive strategies. Imagery is not only the ability to see oneself in the mind's eye executing a skill. It is also the ability to use all the senses - tactical, olfactory, auditory, and kinaesthetic - to re-create and vividly control the pictures in the mind. Michael Jordan (1998) states:

I have used visualization techniques for as long as I can remember. I always visualized my success. It wasn't until later in my career that I realized the technique is something most people have to learn. I had been practising the principles naturally my entire life. I visualized how many points I was going to score, how I was going to score them, how I was going to play and break down my opponent. (Jordan, 1998, p. 64)

\section{Goal Setting}

In both the sports and music literature, goal setting is identified as an essential motivator for successful performance outcomes. According to Leith (2008) goal setting for optimal and peak performance is one of the most highly recommended methods for taking an athlete's performance to the next level. He states that successful elite athletes engage in goal setting strategies to a higher degree than the non-elite athlete. The aim of goal setting in performance is to increase performance ability and outcomes and ensure that an individual continually pushes themselves to their maximum ability. A United States Olympic Committee (USOC) report acknowledged goal setting as a high priority and stated:

How much success do you want? Many athletes achieve some success without using formal goal setting, but virtually every great athlete who consistently wins uses some form of goal setting. Based on our experience, the USOC sport psychology program believes that using 
goal setting is as necessary as having a coach - Sport Psychology Staff, United States Committee (2008, p. 7 (as cited in Kornspan, 2009, p. 45).

Conversely, Marchant (2000) found the application of goal setting could be self-defeating if it was not realistic. He also suggested that the use of small goals often provides the motivation and confidence for taking on bigger and more challenging goals.

A goal setting framework that was often cited in the sport literature ( $L$ Kidman \& Hanrahan, 2004; Marchant, 2000; Shepherd, 2006) was Kirschenbaum's (1997) acronym SMART, (S)specific, (M)measurable, (A)achievable, (R)realistic, and (T)ime phased which he devised to help athletes set effective goals; Shepherd's (2006) considered that athletes should design a relevant and progressive training plan with a designated time frame which included SMART goals. He advised that - "Athlete/coach should establish short- medium- and long-term goals to optimally shape the sports training process. These should meet all aspects of training and competitive requirements" (p.157). Lynch (2001) agreed that reaching peak performance levels means that an athlete must set goals that are meaningful and challenging.

In sport, goal setting is recognised as one of the most effective methods for taking an athlete's performance to a higher standard. It was identified as a specific aspect of motivational theory aimed at focusing athletes' efforts and monitoring their overall progress and success. It was also suggested that for goal setting methods to be successful an athlete must make specific distinctions between the different types of goals. Both process and performance outcomes goals were identified as beneficial in training. Process goals focus on the process of mastering a skill and how competently a skill is completed. Performance outcome goals focus on personal performance in relation to their previous level of ability. Researchers indicated that performance goals are useful for mastering a specific task or skill and as a result focused on how to win, rather than winning itself. Process goals were 
seen as beneficial as they allow the athlete to focus on the actual processes of performing well, as opposed to the result. However, the focus of outcome goals was associated with social comparisons. This type of goal orientation was seen as harmful as the athlete's focus is on the final outcome of a performance event and was a major source of pressure, stress and anxiety (Lynch, 2001; Hodge, 2005; Leith, 2008).

Research conducted by Lacaille et al. (2005) examined elite athletes' and musicians' utilisation of goal setting prior to both peak and low standard performances. For athletes both mastery and performance approach goals were associated with peak performance, whereas for the musicians performance goals were shown to be damaging to performance. Examination of the benefits of intrinsic goals associated with enjoyment found that intrinsic goals were beneficial to musicians.

When examining the effects of performance goals on musicians it was suggested that performance-related anxiety appeared to increase during preparation. It was considered that both performance avoidance goals and performance approach goals were problematic. To avoid goals that caused poor performance Lacaille et.al. (2005) recommended that musicians focus on the intrinsic enjoyment - 'flow' - and be totally absorbed into the music experience. The difference noted between the athletes and the musicians in conjunction with peak performance was goal orientation. The athletes were reported to have utilized performance approach goals prior to a peak performance, whereas the musicians had not applied performance approach goals prior to peak performance. The report also found that both athletes and musicians reported higher levels of intrinsic goals prior to peak performance compared with a low standard performance; this pattern was strongly associated with the musicians but less evident amongst the athletes. It was suggested that a combination of mastery and performance goals could be unfavourable for some musicians. In other words, if the musician's goal focus was primarily on aesthetic and enjoyable aspects of performance it was likely to minimize the negative impact that was associated with achievement goals. 


\section{Goal setting in sport and music education}

As this study has been conducted in an educational context, an examination of the literature related to sport and music education is also important. This section looks at the literature on students' learning and goalsetting methods within these areas.

In both the sport and music education literature, goal setting was identified as a key factor in performance achievement. It was also identified in the educational literature in association with self-regulation learning (SRL). In education it is commonly believed that students who engage in SRL increase their chances of success. Nielsen (2001) found that self-regulation methods had positive effects for music students. She considered that students who engaged in self-regulatory skills set specific goals, engaged in strategic planning, used self-instruction, set task strategies and monitored themselves selectively at a detailed level. She concluded that a supportive social environment encouraged self-regulatory development and provided extensive opportunities for self-directed practice. In later research Nielsen (2008) examined students' utilisation of achievement goal orientation. She found that advanced music students used achievement goals during practice, whereas less advanced students focused on ability-approach goals during practice. The findings suggested that less advanced students were influenced by peer pressure and felt compelled to appear more competent. She stated that educators ought to train students to focus on the tasks at hand during practice and not define their success by comparing themselves to their peers.

In sport education, Marchant (2000) examined the impact of educational history on athletic students' response to learning engagement. He reported that a training athlete may be non-compliant to written work and those educators in sport need to exercise caution when introducing athletes to goal setting because of their previous educational experiences. He believed that resistance can be associated with the athlete's educational history when inadequate knowledge and problems with literacy can occur. It is probable 
that negative memories of school days can reinforce resistance to written work and that students may view homework as a further disruption 'on their already busy lives' (p.94).

In sport education Ravizza (1990) recommended that coaches considered operating standards, and referred to the concept of flexibility and being able to adjust to a situation. He states, "In every situation there is an ideal way to do your job, and then there is reality" (p. 331). For goal setting processes to be successful the coach must take responsibility to ensure goals are reinforced constantly, otherwise the athletes cannot be successful (1990).

\section{Peak performance}

In the sporting domain it is acknowledged that elite athletes are dedicated and motivated to extreme levels of training with the aspiration of reaching peak performance. For those who desire to win and be at their best, hard work and determination are necessary attributes. In the world of competitive sport, peak performance requires physical training and the ability to master the sport through the mind. Hodge (2005) asks the question:

When you play competitive sport are you "playing not to lose" or are you "playing to win"? ... if the athlete's attitude is: playing to win" their success rate is higher. The athlete needs to be made of tough stuff if they are to succeed. $(2005$, p. 6$)$

Since the early 1960s psychologists have been examining the physical and psychological aspects of peak performance and experience. Thorne (1963) wrote that peak experience was "a subjective experiencing of what is subjectively recognized to be one of the high points of life, one of the most exciting, rich, and fulfilling experiences which the person has ever had" ( $p$. 176). Maslow (1968) also stressed the importance of understanding peak experience, as it encourages the development of individual growth. 
The relationship between flow and peak performance was identified as an indicator of peak experience. In 1975 the term "flow" was coined in a highly regarded study by psychologist Csikszentmihalyi (1975). This research involved an exploration of the human state of enjoyment in which Csikszentmihalyi investigated a variety of activities, including rock climbing, surgery procedures and artistic activities. His findings suggest that the state of flow was experienced across ages, gender, ethnicity and social contexts. In later research Csikszentmihalyi and Jackson (1999) defined flow response as a "holistic response" or an optimal state of one's self, harmony and total involvement in the experience. They explained that the flow experience occurred when an individual was totally absorbed in a task that seemed effortless and excluded all other thoughts and emotion. In other words, mind and body worked together effortlessly throughout the activity.

In earlier research, aspects of flow were examined in correlation with peak experience and its connection to skill acquisition. Ravizza (1984) described peak experience as rare moments, which would increase when skill acquisition was mastered to higher standard and that peak performance and peak experience occurred simultaneously. However, according to Privette's (1983) theory of peak components, it is possible for an individual to have peak experience without peak performance. Privette argued that the experience of flow can occur at any level of performance whereas peak performance occurs only at a high level of focus and skill. Jackson (1992) also stated that elite athletes do not experience flow very often, whereas non-elite athletes were more likely to experience flow even though their level of ability was at a lower level. She also considered that flow perspective relates to the kinds of psychological states that underlie a peak performance.

Horn (2008) suggested that further research was required to clarify the specifics of the flow-peak performance state.

Although a close relationship between flow and peak performance is apparent more research is needed to examine the specifics of the flow- 
peak performance. For example, athletes in flow may not always perform at their peak. And conversely, when or how does an athlete perform at his or her peak without optimal mental states such as flow? (Horn, 2008, p. 380).

For the purpose of this present study, it was important to examine the literature on flow within a group setting as participants were performing in bands. Flow state is not only for the individual but can be experienced through group cohesion. Cosma (1999) defined team flow as a "state of optimal experience involving a team's total absorption in a task and a state of consciousness that optimizes performance" (p. 8). He stated that, although flow is experienced by individuals, it does not occur in isolation and rather is dependent on both individual characteristics and contextual variables. Mosek (2009) examined a team of basketball players in the highest level of competition in the youth Israeli basketball league. The findings of this study suggested that team players frequently experienced both individual and team flow and that these were similar phenomena.

In earlier studies on team development and group cohesion, researchers Tuckman (1965) and Carron (1982) introduced models that identify the components of team development and the development of group cohesion. Tuckman concluded that the first stage of team development was 'forming'. This is when team members start to assess strengths and weaknesses and leadership is identified. Stage two, 'storming', is a challenging phase where conflict can occur as members start to identify themselves in the team. Stage three, 'norming', is where hostility is replaced with cooperation and solidarity members start to work together and develop common goals. Finally 'performing' - the team is functioning effectively as a unit. Tuckman and Jensen (1977) later added a fifth stage called 'adjourning' that involved completing the task and breaking up the team.

Carron (1982) developed a team cohesion model that differentiated between task cohesion, such as the commitment to team goals and 
performance objectives. Carron's model identifies group cohesion development and the impact on performance outcomes. The model also included social cohesion, which covers friendship and affiliation. Carron suggested seven factors that were strongly influential on group cohesion. He identified these as:

(1) Environmental - contractual responsibilities and the organisational environment);

(2) Personal factors - individual orientation, satisfaction and individual differences;

(3) Leadership - leadership behaviour and style which also includes the coach-athlete personalities;

(4) Team factors - group tasks and desire for group success, group orientation, ability and stability;

(5) Cohesion - task cohesion and social cohesion;

(6) Group outcomes - team stability, absolute performance effectiveness and relative performance effectiveness;

(7) Individual outcomes - behavioural consequences, absolute performance effectiveness, relative performance effectiveness and satisfaction. 


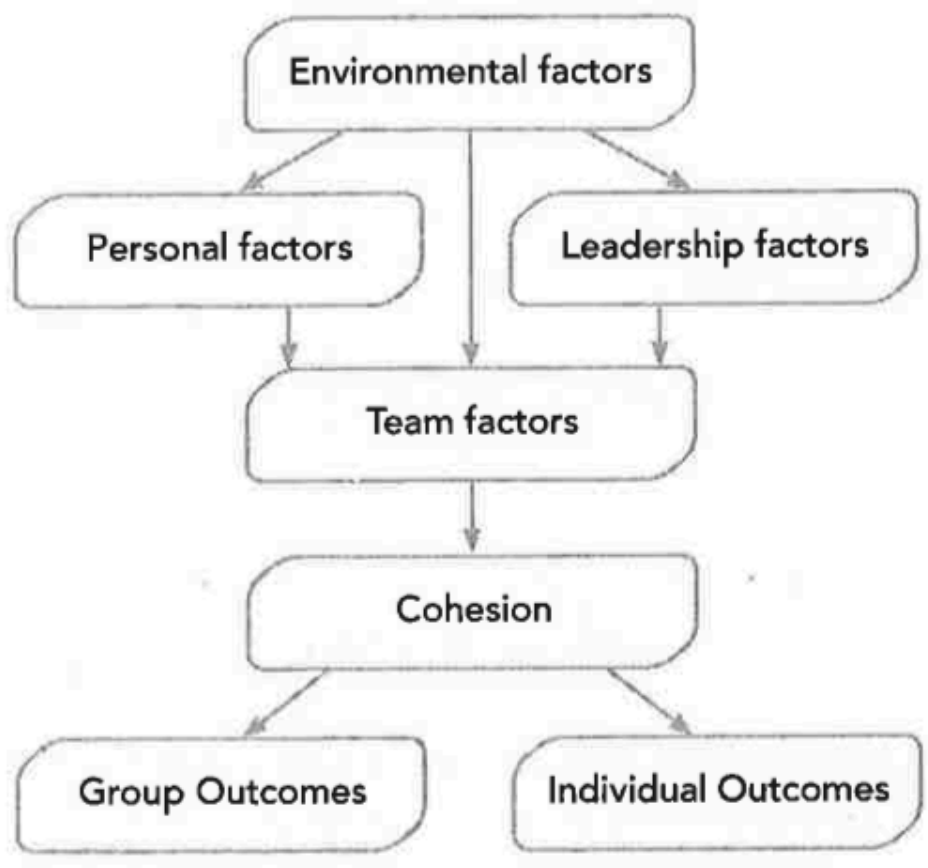

Fig. 2 - Carron's (1982) team cohesion model - Figure 17.7:

Carron's Conceptual Model of Cohesion (adapted from Carron, 1982) Cited in Sports Psychology (n.d., p. 23)

Carron et al. (2002) also considered group cohesion and its effect on both individual and group performance achievement. The experience of flow in a team setting is attributed to athletes who work together towards a common goal and who are intrinsically motivated to experience optimal performance outcomes. They indicated that team variables such as group cohesion were important in optimizing team performance and that a high standard of team cohesion would be positively associated with team flow.

The rise and fall of group cohesion was examined by Burt-Perkins and Mills (2008). They focused on a three-year longitudinal case study which investigated the 'rise and fall' of a chamber quintet. The quintet appeared to work well together in the initial stages. However, as the students prepared the quintet for performance assessment the group lost its previous connection and the members' unity diminished. The results showed that the group's initial shared goals had been put aside owing to performance pressure, which disrupted the group's collective connection. 
Another aspect of interest in the performance literature was performance preparedness for a specific moment in time, such as competition or a performance assessment. In the sport domain, this approach to training was identified in sport terminology as periodization. The design for such a programme is highly sophisticated and multi-disciplined. Holliday et al. (2008) refers to periodization as an important aspect of sport psychology training for athletes competing at an elite level. It is a recognised methodology for training athletes both physically and psychologically for the development of peak performance. The goal of periodization is to maximize long-term athlete development and peak performance for targeted competitions while minimizing training problems such as staleness, overtraining, burnout, and injury. In designing such an advanced programme both the coach and athlete are exact and meticulous in the balance of physical and psychological aspects of training. This is to ensure the athlete will peak perform at the appropriate time during the performance season. In the music domain, performance preparation did not seem to apply the same degree of sophistication which disclosed a significant gap associated with specific event training for singers.

The environmental influence on performance achievement was also of interest to this study. Wrigley (2005) challenged educational practices that did not apply appropriate methods for assessment. This research used a mixed methodology and explored Cskiszentmihalyi's (1975) ideas of 'flow' and Bandura's (1977) theory of self-efficacy. Wrigley's findings indicated that a performance assessment environment was not conducive to optimal performance. He concluded that if students were given sufficient formative assessments to familiarize themselves with the summative assessment experience, then optimal performance was more likely to occur. Wrigley's research supported Cskiszentmihalyi's (1975) flow model in live music performance, finding it to be consistent with research in other performance domains such as sport activities. The self-efficacy evaluation of students was also similar to Bandura's (1977) theory of self-belief. 
Since peak performance is desirable in the final performance for assessment, it is important for this project to consider studies of music assessment. A concern that has led to debate regarding music performance assessment is the role of subjectivity and objectivity and how best to ensure validity and reliability. Mills (1991) addressed this issue, commenting that:

All assessment is subjective, in the sense that human beings determine how it is done. Even the most prescriptive mark scheme for a mathematics problem, for instance, was organised by a human being... The fact that assessment is subjective, in the sense that human beings are involved in it, is surely something to be celebrated, not bewailed. The material being assessed is, after all, human endeavour. (1991, p. 176)

Davis and Pulman's (2001) study on raising the standard of performance in music education recommended that a focus on performance was beneficial to music students. The research found that the musical institutions had focused on practice strategies and individual lessons with less focus on actual performance events. For the purpose of the research, curriculum changes were made including an informal forum where students could perform in front of their peers, allowing for a supportive environment. An increase in the number of public performances was also introduced to assist in developing the standard of students' performance ability. The research found that participating students' self-efficacy and confidence improved with increased performance opportunities. The students produced creative and original ideas for the final performances, which challenged the concepts of performance in that academic environment. As a result of this research, the academy was challenged to re-think its approach to assessing musical performances.

Another area of interest for study was assessment grading approaches used within the music domain. Saunders and Holahan (1997) commented that the use of criteria-specific rating scales has diagnostic value, and instructional benefits that achieve a higher level of accuracy in performance 
assessment evaluation (1997). An investigation into music assessment by Stanley, Brooker and Gilbert (2002) developed descriptors of quality with students that included both a holistic and criteria-specific approach. The investigation suggested that both approaches had challenges for the examiners. Stanley et al. (2002) found that it was common practice for judges to use a holistic approach. This approach was identified by the examiners as a 'gut reaction' by professionals, and this intuitive or emotional response was strongly supported throughout this research. The results from this research suggested that a combination of both a holistic and criteria-specific approach would help deliver reliable and valid evaluations of student achievement. This combination was more likely to provide specific and comprehensive feedback and a fair overall grade to students.

Lebler's $(2006,2008 a)$ research examined a holistic approach to selfevaluation and official grades over a period of three years. In an effort to develop singing students' evaluation skills, students were encouraged to reflect on their strengths and weaknesses. To develop these skills students were required to participate in peer and self-evaluation exercises which related to performances. These results indicated that by developing students' analytical abilities they were better able to deliver meaningful feedback. In Lebler's view this method of feedback encouraged students to take a broader view in self/peer evaluation. This series of studies also showed that students' self-assessment evaluation grades fell within a five per cent range of those awarded by staff. However, other researchers have found that students have a tendency to over grade in peer evaluation because of the influence of peer pressure (Blom, 2004; Daniel,(2004; Searby, 1997).

Latukefu (2010) also examined the impact of peer assessment on students' critical thinking and responsibility. She found that when students were proactive in critical analyses and applied what they found to their own singing the student's personal development was strengthened. This research was supported by the findings of Blom and Poole (2004) who also concluded that peer assessment in a tertiary performance programme offers a relevant 
and meaningful context for deep learning about performance assessment and performing to occur (2004, p. 125). The results suggested that peer assessment opportunities increased the individuals' ability to take control of their own assessment, and analytically assessing peer performances challenged the effectiveness of their own performances (2004). Sluijsmans and Prins's (2006) comments on peer assessment also suggest that students involved in peer assessment design benefit from the experience and found it to be effective and a powerful learning activity.

An area of interest for this study was to examine recognised educational practices which could enhance the delivery of this programme. Biggs and Tang (2007) emphasised the concept of constructive alignment, which encourages consistency in the learning environment allowing for the development of active knowledge creation. Constructive alignment insists on assessments that are authentic and relevant to the students' future needs in the discipline or profession being studied. The assessment tasks must continually build on the previous task, which allows students to develop the skills necessary for the next stage of study. Biggs and Tang commented that tertiary education constructive alignment also includes factors such as assisting students to manage their time and effort and timing assessment tasks to avoid overload.

As this study was set in an educational environment, the exploration factors influencing learning engagement were also worth considering. Mclnerney and Mclnerney (2006) pointed out that surface and deep learning are indicators of students' learning intentions, learning styles, learning approaches adopted and learning outcomes. Surface learners tend to learn in a superficial way often characterised by rote memorisation, whereas deep learners actively seek out ideas for themselves by relating those ideas to previous knowledge and experience. Surface and deep learning are also similar to Bloom's taxonomy which defines an individual's level of engagement to learning. This method of learning was encouraged in the educational domain in order to direct students to move from surface to deep 
learning. To improve students' engagement to learning educators are advised to provide teaching and learning activities that support deep learning. These activities give students the opportunity to engage in reflective learning which can prompt advanced learning (Anderson \& Krathwohl, 2001) .

\section{The Gaps}

The sports literature has an abundance of information on the application of sport psychology methods in the coaching of athletes from the novice to the elite level. There is, however, minimal research on the use of sport psychology methods in contemporary singing training. Aspects such as deliberate practice and performance anxiety had been observed and reported on, but there has been no single study that has systematically introduced, observed and reported the use of sport psychology methods in singing training.

It is therefore, a worthwhile opportunity to research the benefits and challenges of applying aspects of sport psychology methods in contemporary singing education, and observing the effects on participants. The features of sport psychology that will feature in this study are: deliberate practice, selfefficacy, motivation, goal setting, performance achievement and assessment.

\section{Research Questions}

What is the impact of a training programme based on sport psychology for a cohort of contemporary singing students?

Do goal setting, motivation, self-efficacy and deliberate practice have an impact on performance, and if so in what ways?

Do motivation mechanisms increase deliberate practice, and if so in what ways?

In what ways does team flow influence peak performance? 


\section{Programme implementation}

For the purposes of this study a number of sport psychology based techniques and processes were introduced into the singing programme. These innovations were identified from the literature and their effectiveness in the sporting domain was supported by empirical evidence. The pedagogical changes were aligned with the categories discussed in the literature review.

An initial pilot was completed in 2010 with students at the same year level as those who would be involved in the full study in 2011. During this pilot a number of initiatives were trialled and it provided valuable insights into the feasibility of the planned initiative. In the original singing programme students attended a half-hour individual lesson once a week. It was, however, necessary to increase contact time to allow for the introduction of self and peer evaluation. The students were therefore time-tabled for two individual lessons and then the third session was a combined group class. The group sessions proved to be beneficial and were introduced into this project. The pilot participants also designed a personal practice journal to document their practice and personal vocal training journey. This prompted the design of the 'deliberate practice workbooks' for the full study - a sample from book one has been provided in appendix $4 a$. 


\section{CHAPTER THREE \\ Research Process}

\section{Methodology}

Given the nature of the research questions a qualitative methodology was considered the most suitable for the design of this research. The theoretical framework was a case study based on Crotty's (1998) interpretive theory. Denzin and Lincoln (2008) explain that interpretive theory involves an interpretive, naturalistic approach to the world. They considered that qualitative researchers study things in their natural settings, while attempting to make sense of, or interpret phenomena in terms of the meanings people bring to them. Denscombe (2003) suggests that "Fieldwork observation ... occurs in situations which would have occurred whether or not research had taken place. The whole point is to observe things as they normally happen, rather than as they happen under artificially created conditions such as laboratory experiments" (2003, p. 193). As this research was exploring human subjects it required a methodology that allowed the researcher to examine social phenomena in a natural setting. This allowed for an extensive and in-depth examination of the research questions (Yin, 2009, p. 4). The researcher was able to draw on naturalistic data found in the experience of both the teacher (who is the researcher) and the students from one music class. The researcher was enabled to answer the research questions relevant to the investigation.

It is also important that the researcher is able to identify the type of case study and its purpose. Stake (1995) identified three types of case studies: intrinsic case studies (to understand the particular case in question), instrumental case studies (examination to gain insight into an issue or theory) and collective case studies (studying several cases in one study) (1995). Merriam identified the purpose for the case study types as: descriptive, 
interpretive and evaluative (1998). From the case studies identified by Stakes and Merriam this case would be regarded as an intrinsic and interpretive case study.

The theoretical framework and design of this case study incorporated a naturalistic, instrumental, interpretive case study. This framework allowed the researcher to examine the research questions in a natural context and gain insights contributing to interpretation. The bounded system given to the design encouraged a rigorous and purposeful inquiry. For this study, the bounded system allowed for the exploration of one class of contemporary singing students over a whole year. These students were in the first year of an applied arts degree in a New Zealand tertiary institution (polytechnic), and were in the researcher's own class.

A strength and characteristic common in case study is the use of multiple data sources. The use of multiple data gives the researcher an ability to use a variety of methods depending on the circumstances and the specific needs of the situation. This enables verification of data through triangulation, which views the data from different perspectives. The use of multiple sources allows the data to be compared and cross-checked which encourages a thorough investigation of the data (Merriam, 2009). Triangulation can also strengthen the credibility and reliability of the research findings. The principle behind this is that the researcher will have a more in-depth view of what is being investigated from the different perspectives, and this will improve the reliability and validity of the data collected. The term commonly used in qualitative research for using multiple data sources is triangulation.

Triangulation is useful in this type of research as it is more likely to challenge personal bias and interpretation which can help prevent inaccurate and misleading presentation of the evidence. This study used multiple data sources which included: students' workbooks, focus group interviews, video recordings of students' assessment performances and the researcher's personal memoing and journal notes. 


\section{Curriculum Changes}

A number of pedagogical changes, based on the principles of sport psychology, were introduced into the curriculum for the purpose of improving performance achievement.

(1) A specifically designed workbook allowed the researcher to incorporate these factors.

(2) Self-efficacy was observed and considered by self/peer evaluation.

(3) Motivational factors were included in the students' workbook and monitored by the researcher. Students' reactions and experiences throughout the year also gave insight to motivational mechanisms.

(4) Goal setting methods commonly used in sport psychology were included as part of the students' vocal training.

(5) Performance achievement and assessment were directly sourced from students' performance outcomes and summative results.

\section{Ethics}

This study needed to use data gathered from human subjects. Therefore, in order to protect the integrity of the research participants, the study followed the guidelines of Victoria University of Wellington, Faculty of Education Human Ethics Committee.

The main ethical concerns to be addressed were issues around the researcher's position as teacher of the student participants: the relationship between teaching, assessment and the needs of the research. These issues were appropriately addressed in the ethics application. Any data gathering contact with students during the academic year of the research was conducted by a designated colleague. The colleague explained the research project to eligible participants and invited the students to participate. The students who gave their consent received an Information Sheet explaining the background and purpose of the study and their involvement throughout the project. After reading the information sheet participants were invited to give 
informed consent by signing a consent form (see Appendix 1). The students understood that the researcher would have no access to their focus group interview transcripts or performance assessment results until they had received all official academic results.

It was important that the participants did not feel pressured by the researcher to participate or not participate throughout the length of the research. If they had questions or wanted to withdraw from the research at any stage they could contact the supervisor for this study or the designated colleague from the tertiary institute where the research took place.

Ethical approval was received from the Victoria University of Wellington, Faculty of Education, Human Ethics Committee

\section{Participants}

The participants selected for this research were a cohort of contemporary singing students from a New Zealand tertiary institution undertaking a level 5, 20-credit vocal paper, in the first year of a degree. The cohort was represented by all the level 5 students: two male and three female students ranging from $18-37$ years of age. Four of the students had been taught by the researcher in the previous year in a Level 4 certificate course. However, one student had entered this singing course as part of his final year of the degree programme. None of the participants had prior formal singing qualification before entering this programme or were familiar with deliberate practice methods.

The rationale for selection of this particular group was their year of study. Firstly, the group was familiar with the researcher and had completed a certificate qualification in 2010. Secondly, the students were committed to further their singing studies. Thirdly, the level of study for this project was the first year of an undergraduate applied degree. This was considered an 
appropriate time in the students' study cycle to introduce new training strategies.

\section{The Researcher}

The researcher's educational background included an under-graduate degree in jazz performance and a postgraduate degree in singing teaching. The researcher's previous experience had been 20 years of working in the music industry as a lead singer in various bands. Her vocal teaching experience has been gained over the past ten years at the tertiary institution at which this research has been undertaken. The researcher has relied strongly on personal experience from her professional singing career when training undergraduate contemporary singers. This would be typical of other contemporary voice coaches in New Zealand who would not have obtained a formative qualification such as classical voice teachers.

The challenges in this research were to ensure the credibility and reliability of the researcher's engagement and intent throughout the research process. The first challenge was the researcher's ability to maintain an objective perspective throughout the research. The relationship built between the researcher (teacher) and participants (students) had the potential to create bias because of the dual role required. The second challenge was ensuring that the research project did not interfere with the students' learning outcomes. It was imperative that the teacher and researcher roles did not adversely influence their results. The last challenge was ensuring that the research project processes were ethical and all aspects were followed professionally in order to prevent the data being corrupted in anyway.

\section{Data Sources}

The data were collected from five different sources - workbooks, focus groups, assessors' feedback, the researcher's personal journal and video recordings from the participants' performance assessments. The workbooks 
were collected at the end of each term for review and were kept by the researcher. Focus groups were attended by the participants at the end of each semester. This allowed the participants to discuss the sport psychology related methods and their appraisal of programme changes. The researcher documented personal reflective notes during the year. She used both memoing and journaling to ensure her recollection of events was accurate. Finally, the students' performances were video recorded for the purpose of review.

\section{The workbook}

To help follow students' progress throughout the academic year - in a 'natural setting' - four workbooks were designed, one for each term. These books were designed as training logbooks to record student's levels of participation in both class time and individual practice. The content of each book incorporated the original vocal programme with the additional sport psychology methodology. A sample examination paper was provided in the back of each book which gave precise guideline to each term's study and examination requirements. Term one and terms three included technique, musicianship and performance skills while term two and term four were the vocal programme design with performance assessment criteria. The students involved in this study gave the researcher permission to use the workbooks as part of the data collection.

\section{Focus groups}

July 2011 focus group 1 - FG1

November 2011 focus group 2 - FG2

The focus group questions have been provided in Appendix 2a and 2b.

The focus (FG1) questions were sent to all participating students a fortnight before the focus group meeting. The rationale for sending out the focus questions was to give the students an opportunity to view the questions 
and reflect on them before the meeting. However, this proved to be detrimental for one of the students who misunderstood the intent of the researcher. The student thought that the questions were to be answered in writing and then sent back. The student was overwhelmed by what he considered were the researcher's expectations and nearly withdrew from the research project. A meeting with the student re-explaining why the questions had been sent reassured him and he chose to stay in the research project. The second focus group (FG2) questions were not sent out prior to the interview to ensure students were not confused by the questions before the focus group meeting (appendix 2a, 2b).

\section{Researcher's memos and journaling}

Throughout the year the researcher compiled reflective notes in the form of journaling and 'memoing' (Johnson \& Christensen, 2008). Memoing is useful for recalling emergent ideas and valuable information. This method of documentation allowed for an improved accuracy of direct observation in the analyzing process. To ensure the information collected from the students was focused and specific to this project, the researcher used a memo formula which was based on the original data collection model - GPS-MAD (Appendix 3). The acronym was formulated from the categories identified from the sport literature. These categories were goal setting, performance, self-efficacy, motivation, assessment and deliberate practice. This was specifically used in the students' individual lessons. It allowed the events written in the researcher's journal to be precise and creditable.

\section{Video recordings}

Video recordings were made to keep hard copy evidence relating to performances to ensure the data's reliability. No analysis of the digital recordings of students' performances occurred until the end of 2011 after all assessments was marked and results had been submitted to the appropriate Board of Studies - as stated in consent process. The benefit of using video recordings was to give an in-depth view of the students' performance 
achievements. This observation method allowed the researcher to examine the students' perspectives and her own interpretations accurately.

\section{Assessment results}

All the participants' assessment results were collected throughout the year. These results were used for analytical purpose and were influential to the overall findings.

\section{Data analysis}

Denscombe (2010) states that qualitative data analysis is the process of bringing order, structure, and interpretation to the data collected. To bring order and structure to this studies data analysis process a coding system was designed which employed the acronym GPS-MAD. As mentioned earlier, these categories were goal setting, performance, self-efficacy, motivation, assessment and deliberate practice.

The data was then interpreted by themes and trends which were colour coded under the appropriate file of the acronym GPS-MAD. This allowed the researcher to cross check tentative findings and isolate the major themes and trends found within the data collection. The researcher's personal notes and memoing and the focus group interviews transcripts were investigated for similarities and differences. After these results were studied further observational comparisons were achieved by reviewing video recordings of participants' performances. The assessors' feedback from the performance assessments was also analyzed with the other multiple sources. The researcher examined these findings to see whether or not any significant differences directly associated with sport psychology methods were identifiable. 
Credibility and trustworthiness

To ensure the credibility and trustworthiness of this research project it was important that the data collection process was meticulous so that the final results were reflective and reliable (Yin, 2009). To avoid any data being invalid, ethical issues were adhered to throughout the research project. Credibility was also checked by comparing the analysed findings with similar themes or trends reported in the literature. 


\section{CHAPTER FOUR FINDINGS}

\section{Introduction}

The following chapter will present the findings under the five major categories and emergent themes. It is acknowledged that while these are presented as separate categories; the reality is that all five will interact with and influence each other. For ethical reasons, students' names have been changed for the purpose of this investigation.

\section{Deliberate practice}

Four deliberate practice workbooks were designed for the purposes of implementing training methods, commonly used in sport psychology. The students were required to use the deliberate practice workbooks as a practice journal and to document their progress. The aim was to encourage deliberate practice and improve student's practice habits. The findings showed that the implementation of a regime of deliberate practice was not as straightforward as first anticipated and proved to be a challenge throughout the academic year.

Deliberate practice - the workbook

At the beginning of the year all participants were optimistic and prepared to trial the new workbook. However, within the first week it became obvious 
that the students were reacting to the use of the workbooks in a wide variety of ways. These reactions ranged from a complete rejection of the workbooks through to full acceptance. The immediate disengagement from some of the participants was a surprise to the researcher and unfortunately the battle to get students using the workbooks continued throughout the entire year.

Sophie was the student who found the use of the workbook the most difficult. She felt the singing lessons from the previous year were more supportive and focused and found the structured implementation too precise and over-loaded, even frustrating. She viewed the deliberate practice workbooks as being designed for the purposes of the research and indicated her belief that they were irrelevant to her vocal study. Her comments in the focus group 1 (FG1) showed her concern at the new approach and her belief that it was having a negative impact on her learning - "she should be teaching us, as opposed to her thesis, if you know what I mean?" Sophie also found the additional documentation requirements difficult - "I am not a journalkeeper, I just do it." Sophie did not compromise her stand and chose not to use the deliberate practice workbooks as directed. She also mentioned "Yeah, it's just for different personalities. I just find it really hard. I do, like my own sort of practice...I just never write about it."

Sophie did suggest a different method of training that while involving deliberate practice would focus on one specific exercise each week, stating "So, I think, that would be really helpful, I know just for me personally, like, it would be really cool to work on something specifically each week." Her suggestion was implemented in individual singing lessons during term three and term four. In the $2^{\text {nd }}$ focus group she commented that the new approach had been worthwhile - "I've really enjoyed the lessons because it's been really physical and hands on and really working. Cause, finally....instead of just the book sort of stuff. The lessons have been really good." Although Sophie's engagement improved in singing lessons her commitment to personal deliberate practice was not evident. She continued to do her own 'sort of practice' which involved learning repertoire relative to her up-and- 
coming performances and did not engage in any deliberate practice. This meant the lessons were productive in regard to repertoire but because of her approach to practice she neglected the aspects of vocal programme designed for progressive training. Sophie's singing level did not show any significant changes during the academic year.

In direct contrast to Sophie, Pam found the workbooks to be beneficial and supportive to her study and yet she also experienced set-backs for different reasons. She was convinced the deliberate practice workbooks kept her study organised and reflective - "I felt lost last year and didn't really know what I was doing week-to-week. I feel more organized with these changes. I feel less pressure when it comes to skills tests also. The workbooks have worked for me and the deliberate practice shows me if I have neglected my work or not. It's a good workbook to read over and reflect when you get time. Yeah, the book is good. The book is really good." However, she rarely brought her workbook to singing lessons and was indirectly disadvantaged as she did not communicate the difficulties she experienced with the music theory and musicianship elements of her vocal studies. While the use of the workbook helped her maintain a programme of deliberate practice, this failure to communicate difficulties identified limitations in its overall effectiveness.

However, it was interesting to note that whenever any of the students applied the principles of deliberate practice their singing did improve. Conversely, as soon as these principles were abandoned the level of progress was notably interrupted.

An example of deliberate practice principles working when applied was identifiable in Matthew's case. In FG1 he was asked if he would remember what he needed to do if he did not have the workbook. His response indicated that he had found the task laborious and preferred not to do it. "It is something I just need to keep on remembering all the time." Matthew scored a competent grade $B$ in his skills test because of his previous musical knowledge. However, in the later part of the academic year Matthew did 
mention that he had tried to practice with the workbook. From FG2 he said "Um, I need the discipline to actually write in it every day. And at the beginning of the year I did not use it. I just hated it. But then I gave it a shot and I could write things down and remember them." He also found the workbook was beneficial to the individual singing lesson. Matthew said - "It would be easier in the lessons. And Sandy would just point out what I needed to work on." Matthew only used the workbook intermittently which did not encourage progressive vocal development.

\section{Deliberate practice - music theory}

As deliberate practice is designed to integrate both physical and psychological aspects in sport training it was appropriate to include music theory. The researcher's empirical knowledge showed the need to support singers in music theory study. The singers often found it difficult to make sense of music theory and its relativity to singing. However, the findings indicated that some of the students viewed music theory as an additional component to the vocal programme and suggested that the study requirements were unrealistic.

Pam mentioned that the major theory class and vocals were not in sync, and consequently found music theory a challenge. The theory was taught over one semester which proved to be unfavourable for the majority of singers. The timeframe was too limited for those students who struggled with this subject.

Luke felt that it should be removed from the vocal programme as there was too much to cover with such limited time. His level of entry to the course could have been a contributory factor to why he felt overwhelmed with the course requirements. In FG2 Luke said "I have only been learning singing for one year and I am still finding my own voice. I'm still working on the basics. I think it covers too many things and half an hour is not enough time." He said 
- "I think it just needs separate theory stuff cause, half an hour weekly lessons not enough time to cover everything."

However, Sophie indicated that music theory was a necessity and beneficial for singers - 'it's the sort of stuff you'll need to know to be able to like, jump in on bands and you'll need to know the key signature and scales, if you're doing like a jazz scat then you know that this key can go on top of this, and things like this. So I think that really helps, definitely. I think it's just too much in one go."

The participants' personal feedback and summative assessment results indicated that the music theory course was too advanced for this level of study. Further discussion on music theory and its relevance to the singing programme will be included in the following chapter.

\section{Deliberate practice - natural talent}

Another aspect associated with deliberate practice was the relationship between it and students' natural singing ability and performance achievement. The performance results showed that students' natural singing ability was a major contributory factor to achieving success in this programme. At this level of study it appeared that students could achieve the performance criteria through natural talent. However, despite being able to pass, the results showed that natural talent was not enough to sustain or improve students' skill acquisition. Without deliberate practice application some students actually declined in their levels of performance. This was particularly noted with students who had previous performance experience and appeared confident in a performance environment. The students with natural talent nevertheless acknowledged that deliberate practice was desirable but found it difficult to implement. The connection between natural talent and educational levels in view of Howe et al.(1998), and Bloom's (1985) research will also be discussed in the following chapter. 
As mentioned earlier, Luke's course entry was different from the other students' as he had selected singing as a second instrument study as part of his Body of Work (BOW). The vocal course was a challenge for him as he had limited natural ability and had no previous singing knowledge and experience. He was highly motivated and acquired additional vocal lessons to support his learning. Luke was dedicated to using deliberate practice methods. Recorded memo notes suggested that Luke's application to the workbook was really good and he had expressed to the vocal coach - "all instrument studies should use the same type of workbook to improve the programmes delivery." His documentation was clear and precise which improved the time management and productivity in the individual lessons. In the first semester Luke's personal development was progressive and he achieved a $\mathrm{C}$ grade which was an excellent results considering his entry level.

\section{Deliberate practice - the environment}

When the students were asked in FG1 about their daily deliberate practice routine, some remarked on their vulnerability while trying to practice. They felt that they were too exposed in the environment when participating in personal practice and because of it they were extremely self-conscious. Some students also suggested that without a soundproof room it was impossible to practice effectively. Sophie said "that environment is hard; it's hard to be kind of 'on' because you're singing along to a c.d. and a microphone and you've got all these people." Pam concurred with Sophie and remarked on her personal issues within the environment stating - "At times when you're required to sing really loud and to kind of belt it and to hit the high notes and not to kind of...yeah, it's definitely hard ...especially if you can't do it and are getting it wrong."

Debbie's comments supported Sophie and Pam - "I don't know if any vocalist practises every day even though we should...There should be soundproof rooms especially for vocalists as we get really self-conscious because everyone can hear us". However, as the academic year progressed 
Sophie felt that she was finding it easier but would still prefer a soundproof room - " Like, you know, yeah that's a lot easier for me. But definitely soundproof." On completion of this study soundproof spaces were still not available at the institution or in the participants' personal environment.

Conversely, Luke and Matthew found the environment a positive training space. Luke explained - "I don't mind doing that because after lessons, I feel more confidence when l'm singing. As I haven't sung professional it helps me not to be scared of singing now." In regard to the environment Matthew showed no signs of performance anxiety and would confidently vocalise anything that was suggested in his lesson.

It was interesting to note that when students were practicing in a band situation, performance anxiety related to their practice environment was not a problem for any of the participants. They felt that practicing repertoire with a band made them feel safe. Sophie said - "it's really cool. And it feels like more 'fun'." Pam commented that with a band "you're supported." The band practice setting reflected a real performance situation and therefore gave the singers a realistic practice environment. Individual practice seemed to make them feel vulnerable and as a result they were reluctant to practice.

It was also found that students were not practising exercises such as visualization, music theory and other element of the vocal programme that did not require vocalization. The comments made by students from FG1 and FG2 - "I just do it" or "I just practice the songs" suggested that the idea of a singing programme that required deliberate practice in these areas was not perceived as important. The data revealed that by the end of the academic year all students had discontinued the use of the deliberate practice workbook and were not engaged in any prescribed vocal practice except for that of learning required repertoire. 


\section{Self-efficacy}

\section{Physical and psychological balance}

In sport the idea of physical and psychological balance is viewed as necessary in effective training. Without this balance it is unlikely an individual will reach their full potential. Sophie was a competent singer with a real passion and self-conviction to being a performer. Her self-belief seemed to support Leith's (2008) statement directed at athletes who exercise sport psychology methods - "I can do this, and are successful regardless of the situation" (p. 20). Leith's statement was in part, reflected in this research but it was not so convincing in Sophie's case. Notes from her workbook suggested that her vocal competence was blurring the lines of her physical and psychological training. In other words, her body-mind connection still needed to be balanced and developed. The problem was that when Sophie performed on stage, her stage persona was not as convincing as her vocal ability. Her performances seemed reserved and disengaged from her audience. Although she did not openly struggle with self-doubt or performance anxiety it was possible that these factors were an underlying cause of her existing performance ability. Her statement from FG1- "I've been singing from the start of last year, like, so it's still quite new to me" could suggest that her level of self-confidence was not as secure as her capabilities might suggest. She needed to strengthen her stage crafting skills to equal her vocal ability. Sophie wrote - 'I need to up my stage craft. Although I don't see how stage craft can up marks for people that haven't got good vocals. And I want to connect with the audience on a more personal level, instead of blinding them with dance moves, explosions and crazy costumes.' These comments could suggest that she was challenged and at the same time confused on what she needed to do to produce a higher performance outcome. On observing Sophie's performances, her programme manager, who was also an official assessor, recommended the following -

I feel Sophie performed with pleasing vocal accuracy, power and musical expression, but was still somewhat inhibited in performance. 
Sophie has been encouraged by us to become more outward focused in performance. It would be interesting to know how engaged she has been with the visualisation side of the research methods.

In response to this feedback Sophie deliberately sought out opportunities to perform with her peers. And because of her vocal competence many of her peers chose her to sing on their performance assessments which allowed for increased performance time.

In contrast, Debbie and Matthew were experienced performers, who demonstrated high self-efficacy beliefs even though they had limited vocal ability and performed only in their comfort zone. As a result their stage crafting skills seemed to outsmart their vocal ability. These students relied strongly on their performance history and did not significantly change their practice behaviours to enhance singing performance levels.

\section{Self-efficacy - the social environment}

As mentioned earlier, group sessions were implemented into this programme with the intent of increasing contact time and to give students opportunities to practice self- and peer- evaluation. In the sport domain constructive self- and peer- feedback is viewed as an essential component to progressive development. From the focus group discussion participants agreed that group sessions were worthwhile and constructive but at the same time challenging. Matthew said - "I find that very helpful and we get a whole hour as well." When the interviewee said "Yes, and in a group you learn from what's said to other people, as well as what's said directly to you." Sophie's response indicated the challenges and said - "It's kind of hard though in that sense 'cause it's like, your peers and your friends. So to be, like, completely honest is quite hard sometimes...cause you don't want to hurt people... or you might be a bit more biased or things." Sophie's comments strongly support Marsh's (1984a) 'big fish little pond effect' (BFPLE) which will be discussed in the following chapter. 
The findings also showed how these students had analysed their performance achievement and assessment results. The students indicated disappointment in their performance assessment grades and in their opinion the assessing panel had graded them too low. On further discussion it was apparent that students had compared their performance with those at the same study level. From the comparisons the students illustrated that their performance acquisition had been of a higher or equal standard and yet their official grade did not reflect their opinion. They were given the opportunity to review their performance and were encouraged to grade their performances with the exact 'criteria grading sheet' (appendix $2 b$ ) used by the professional assessing panel. The students' self-evaluation when they reviewed their performances in this way supported the official grade and this was a surprise to those involved.

\section{Self-efficacy - preparedness}

In the sport domain DeVenzio (1997) was convinced that "confidence level mirrors skill level" (p.91) and suggested that high levels of self-efficacy in performance reflect an athlete's preparedness for an event. In this study, DeVenzio's findings were generally supported but additional aspects influenced Pam's performance assessment experience. Her confidence and skill levels were of a high standard and her preparation for both performance assessments showed dedication and appropriate preparedness effort. However, Pam indicated that the availability and variable ability of her accompanying musicians left her feeling under pressure. She said "I feel under-rehearsed!!! And I feel like I'm putting a whole lot of pressure on my band to help me pass." Although Pam's self-confidence and personal preparation were high she was affected by uncontrollable factors in the musical environment and paid a high price. This suggests that selfpreparedness is only one aspect of performance achievement. If Pam had selected the professional musicians for both performances she would most likely have achieved a high grade in both performance assessments. It is 
worth considering that group cohesion is strongly influential on an individual's performance outcomes.

\section{Emergent theme - vocal coach/ singer relationship}

In the sport domain, the coach/athlete relationship is recognised as a foremost aspect of performance achievement. The findings from this study suggested that the development of a quality relationship between the vocal coach and singing student was disadvantaged because of the limited contact time. From the first focus group interview (FG1) Sophie said -

It's not enough time to build a relationship with the tutor if it's the first time you've been around as well. I remember the first year I came here and I was just, I didn't relate to her. I didn't connect with her until about the end of the year. You don't feel that building of relationship which is so important.

Debbie also expressed her disapproval on how the limited contact time was impacting on her learning (FG2) - "Like we are all actually working in a process of working. Unfortunately, half an hour a week, I think it's ridiculous. It's ridiculous. It's just not enough. What about trying to have one hour?"

The results also indicated that one of the participants perceived the tutor's personal approach as biased. Debbie's feedback (FG2) -

I had the feeling that sometimes she would care for her best students and not care for others...She's really, really awesome to work with...yeah she needs, to make us all feel like we all different individuals, we all have our skills, but we all have our difference in vocal. And just work with us, as every time there is a new student she just treats them equally as the other one. 
This result concerned the vocal coach and action was taken immediately to resolve Debbie's sense of bias and discrimination. The following chapter will review this issue and make suggestions on what could foster and improve student/vocal coach relationship, in this educational context.

\section{Motivation}

Intrinsic and extrinsic motivations are widely discussed in the sport domain as a key component in peak performance. Extrinsic motivators include the direction given from an authority figure - coach - which allows for constructive feedback. It is also common practice within sport training to observe those who are experts from the same field. It is recognised that different motivation approaches are fundamental to progressive development. Performers who are highly skilled have high levels of harmonious passion which plays a major role in sustaining them to reaching expert levels. An individual's level of passion and the degree of autonomy was also recognised as a driving force behind intrinsic motivation (Vallerand, 2003). In sport psychology, constructive feedback is acknowledged as a key component in performance outcomes as it allows the coach and athlete to review all aspects of the performance and ensures progressive development (Becker \& Wrisberg, 2008).

\section{Extrinsic motivation}

An important matter expressed by participants was the need to improve the vocal tutor's availability for the purpose of constructive feedback. From the FG1 they proposed that the vocal coach be present during their weekly band workshop lesson. Pam said - "I'd like to see her come to our band, actual bands, ' cause she came in one time, and came up behind us and it was kinda like 'do this' and she like lifted the whole song. I think that's what she needs to do is come to more of our band sessions." They were also in favour of the tutor attending all of the vocalist performances in conjunction with the institution; for insightful feedback. The absence of the tutor was 
noted by the students' and they expressed their disappointment and felt that by attending the performance the tutor would gain invaluable insight into their vocal development. Sophie stated: - "yeah, I was a bit disappointed and I kind of...it's like she doesn't really know if we're progressing. Because she doesn't see it, because we're not singing in our lessons, so she just doesn't know where we're at, you know what I mean? Until our mid-year or end of year assessment." Sophie also mentioned the positive impact she had experienced when the tutor had been at the performance and stated: - "but she has come to some gigs this year which has been good and always comes up afterwards and feedback and things and...yeah. So I'm happy to see that." Pam also mentioned that the feedback was honest - "Like she'll give you honest feedback as well. Like, 'that was crap', or 'that was really good', and she'll tell you why. You need that."

A disappointing result was the implication of negative feedback. One of the big events in the year, which took place in term three, was a musical production. In 2011 this production was focused around a schools tour and involved both academic staff and students. The singing students stressed at times they had felt disempowered and demoralised during the planning process and rehearsal time. The educational environment was not supportive and they felt they had no personal in-put into the production. When Pam questioned the staff and instrumentalists on chosen repertoire she was rudely told to sit down and shut-up. Pam's comment from (FG2) - "Nah, I just got told to sit down and shut up. I was just a singer." After Pam had experienced this level of implied criticism her vocal studies and performance achievement declined.

\section{External observation}

Beltman's (2005) research supported external motivational factors identified in this study. A statement by Sophie from the $2^{\text {nd }}$ focus group (FG2) was directly aligned to Beltman's findings. Sophie said - “...like seeing people that are really good and it will motivate you to kind of want to improve 
like that." As part of the research the students were to observe world-class performances and feed back their findings and any inspirational factors from performance observations. Pam studied the performances of a well-known Rhythm and Blues singer, Jennifer Hudson. The following is an extract from Pam's deliberate workbook - 'her emotions are expressed through her singing. Very beautiful voice (love her high notes).' From this observational information Pam initiated an action plan to help motivate her own training 'work on my own vocal range - by doing octaves with Sandy on keys. Get Sandy to push me to the limit. Be able to hit my high register without cracking or being too scared to push it.' The memo notes indicated that whenever Pam made an action plan her intent was indicated but her actions were spasmodic and therefore, her skill acquisition levels did not significantly progress.

\section{Intrinsic motivation}

Debbie voiced her passion and dedication to singing at FG2 and said "trying to live from music would be awesome and that would be an achievement in itself. Like, for instance, being a teacher... having your own band and tour...you [sic] still making a living out of music and you're still involved, that would be awesome. That's motivation." On viewing Debbie's performances from both live and video recordings she was a strong competent entertainer and her stage performance and presentational skills were competent. However, Debbie's deliberate practice application was insignificant throughout the academic year and it seemed that her natural ability was enough to sustain her at this level of study. She may have been intrinsically motivated but it was not enough to drive her to expand her vocal ability. Debbie did just enough to get through the vocal course and no more which meant that she was learning at a surface level (Krause, Duchesne, \& McMaugh, 2010). 


\section{Passion}

In the sport domain, passion levels are acknowledged as an important factor in assisting an individual's level of perseverance and without passion it is likely an individual will drop out (Lehman \& Gruber, 2006). Matthew started the year full of enthusiasm and commitment to his studies. He found his individual singing lessons positive and felt supported by the vocal coach mentioning that - "she gives good compliments." His study ethic was commendable and he continued to progress in his vocal studies. However, after the first semester there was a serious change in Matthew's motivation and attitude. In reference to Matthew's workbook he wrote - "life problems unmotivated you". From earlier discussions, he commented that his greatest love was to entertain people. He wanted to be the best entertainer in New Zealand and explore the possibility of heading to Australia for performance experience. On further discussions it was not only his personal life that caused his despondency but also issues within the educational environment. Memo notes mentioned that Matthew was strongly opposed to some music course papers. He had not seen the relevance of the paper and refused to attend class. Inevitably Matthew's studies were compromised and caused him to retreat from all aspects of the course. His negative response may have been avoided if he had had a sense of autonomy within the educational environment. His loss of passion and motivation impacted excessively and he declined the invitation to return to the music course to complete his applied degree qualification. Matthew's negative experience had an impact on his performance. This could be explained by the ideas of Mageau, Vallerand, Charest, et, al. (2009) who concluded that passion plays a major role in sustaining individuals' efforts in reaching expert levels. Sadly, in this case Matthew's passion for performance was not enough to sustain him.

\section{Goal setting}

In the sport domain, goal setting is used for the purpose of progressive development. For progressive development to occur a correct pathway must be devised and adhered to which incorporates appropriate goal setting. In 
sport the most favourable goals identified are progressive and performance goals which supported Kirschenbaum's (1997) SMART framework. For the purpose of this study, participants were to use Kirschenbaum's (1997) SMART framework which implies the use of process and performance goals. (S)pecific, (M)easureable, (A)chieveable, (R)ealistic and (T)ime phased; commonly used in sports' training.

The following examples from the students' workbooks indicated that SMART was not incorporated into their vocal studies. Some of the participants wrote down intention goals, however the students did not engage in the application specified by the SMART goal setting methodology. An example from Matthew's workbook - 'building up an originals band famous for New Zealand' - Matthew set a long term goals that would see him in the national music industry as a top class performer. However, he did not indicate how he was going to achieve his long term goal. With the application of SMART Matthew would have employed a realistic goal process; however he chose not to apply this goal setting method. In contrast, Luke listed his short-term goals. This example is from Luke's term one workbook - week 5: (1) band practice, (2) watch John Mayer for ideas on stage crafting, (3) memorize all songs. The correct goal orientation was identified by Luke but because the goal process was not consistent his progressive development was not achieved.

\section{Goal orientation}

Conversely, outcome goals in the sport domain are acknowledged as unfavourable as they refer to standards of performance that focus entirely on the final result of winning or losing. In this case, students' were fixated on performance assessment repertoire and less focused on other aspects of vocal training. The question most frequently asked by the students throughout the academic year - "can you listen to my performance assessment song?" This frequent questioning was supported by the students' comments from the FG1 - "our singing lessons should focus on our 
end year's or mid year's" - emphasizing what students' perceived as relevant to their singing training. The challenge was to try and direct students to a deeper sense of learning as surface learning was less favourable in peak performance achievement. Ability-approach goals which are also unfavourable to deliberate practice were identified in this current study. Students who experienced performance anxiety associated with practice were indirectly applying ability-approach goals. It was noted that these students were more concerned about peer opinion than self-development which was aligned with the findings of Nielsen (2008). It was concluded that participants were applying outcome and ability-approach goals which are deemed unfavourable for progressive development but also indicated the students' level of study. These results lined up with the known situation; that the participants were not at an advanced level.

\section{Performance}

One of the objectives of this present research was to examine students' performance achievement while reflecting on the implementation of sport psychology.

\section{Individual - peak performance}

In focus group 1 (FG1) participants' were asked if they had experienced peak performance and if so, what was the feedback from the band when it happened - Do you get feedback from your band when that happens? Pam answered - "they don't really hear, it's usually from the members of the audience you hear it from, not the band." These comments inspired an emergent theme on the impact an audience has on performance arousal which could potentially induce a peak performance state. This finding will be considered in the following chapter.

The interviewer also asked whether they had more sense of hitting a peak in their assessments from other performances this year. Sophie said "Yeah, if you're confident with what you're doing, then it's...awesome. Kind of up on cloud nine...having a good time." When Sophie was asked where she 
had sensed a peak performance she said - "Yeah, my mid-years, when I did a Geoff Buckley tune, I think that's been my best vocal performance. Yeah, I just like, completely in the moment and things like that; it was quite an experience." Sophie believed she had experienced peak performance during a performance assessment which differs from the findings of Wrigley (2005). He concluded that peak performance was unlikely to be experienced in an assessing environment. When asked what she would need to do to make that happen again she stated - "...it was lyrical content, and kind of the way the music kind of swelled and things...just all the emotions just came up and it was crazy. Yeah, I guess it just really depends on the song." It was interesting to note how Sophie was referring to her strong connection to the song which she interpreted as peak performance. Another interesting comment from Debbie in regard to peak performance was her level of confidence in her ability to achieve peak performance levels. "Yeah, I'm looking forward to my end of year performance assessment. I think I'm going to do something good. Because I have improved a lot this year...I had, almost tears like to my eyes and stuff, because it's a song with a lot of meaning to me, and I was feeling it at the time." These findings suggested that the students' identified peak performance because of a strong emotional experience. This finding supported Jackson's (1992) point of view who considered that the inexperienced performer will sense peak performance more than the elite performer.

The students were also asked in the $2^{\text {nd }}$ focus group (FG2) what would be a hindrance in getting to a peak performance. The results were surprising as the purpose of introducing sport psychology was to engage students in their mental preparation for performance. Pam said - "motivation for one and issues...negative self-talk." Sophie mentioned - "Mental. Just like having mental roadblocks." Debbie felt it was song choice that would encourage or hinder peak performance - "I think, first of all, loving the song you are doing. So, I think first of all when it comes to the choice of song, and then the band you're in." These statements support sport psychology application and were 
included in the deliberate practice workbook, but the findings showed they did not develop these skills.

\section{Group cohesion}

When Sophie was asked whether the band members noticed her peak performance she stated that - "they don't really hear you because they are doing their own thing." The participants' may have felt they were experiencing peak performance but this did not necessarily mean the audience or band members were sensing this was occurring. On the other hand, the performer themselves might be experiencing performance anxiety and yet the spectators may well sense 'flow' or peak performance. These findings imply that peak performance is subject to subjectivity itself which is therefore influential on performance achievement.

In this course instruction in performance skill was incorporated into band workshops. At the beginning of the academic year musicians and singers were integrated into bands which did not change throughout the academic year. These bands rehearsed four hours a week under the direction of academic staff. For performance assessments students were required to invite musicians to perform on their assessments. The bands were formed so late and rehearsal time was over such a short period and the results showed that these put together bands were musically compromised. The difference between formative and summative performance results was reflected strongly on musical ability and direction. Tuckman's (1965) theory on developing group cohesion - forming, storming, norming and performing - was apparent amongst music students' interaction and connection during performances.

The performances directed by academic staff intensified rehearsal and preparation as staff endeavoured to accomplish a high standard performance. This preparation was taxing but produced excellent results. Most of the participants' expressed that they had thoroughly enjoyed the level of expectation and, even though exhausting and challenging, enjoyed the final 
results. Sophie said -"I liked our last like full week of rehearsing, like it was really cool to build up the vocal stamina, cause we've never really done that before." Debbie also stated - "That was awesome to rehearse from nine to five...and doing it."

It was also noted that Matthew performed to a high standard during the production which showed his professionalism and his ability to entertain. His level of expertise and leadership was seen to promote group cohesion within the band. However, Matthew's reflective comments from the performance were quite the opposite which suggested he had felt overwhelmed and perplexed during his performance. He mentioned that he had felt bullied and forced to sing repertoire that was not suitable. Because of this he considered he had lost his passion for singing and would not be returning to complete his studies in the future.

It is not uncommon for students to experience disillusionment while pursuing their music qualification. It appears that Matthew's expectations and values were challenged in the educational context and consequently interrupted his passion and motivation for singing. From memo notes of 2011 the researcher expressed - 'it's as though their lollies have been taken away and everything is now hard work.' To try and improve practice engagement students were encouraged to set aside some fun time in their practice sessions to ensure they kept their passion for singing alive. The results did not indicate any evidence to support this recommendation as they did not take up the suggestion and therefore cannot be supported in relation to practice engagement and performance achievement outcomes.

\section{Self and peer evaluation}

Group sessions were introduced into the vocal programme to develop students' analytical skills. The results indicated that students found the group sessions beneficial and yet challenging because of peer pressure. The participants were asked at focus group one (FG1) - "How do you feel self and 
peer evaluation have gone in your groups?" Matthew said - "I find that very helpful having a second opinion and we get a whole hour as well." Sophie said - "Yeah that is actually my favourite lesson. But it's kind of hard though in that sense "because it's like, your peers are your friends. So to be, like completely honest is quite hard sometimes. Cause you don't want to hurt people or, you kind of...or you might be a bit more biased or things." When the question was asked "how do you feel about being asked to evaluate yourselves?" Pam said - "I don't mind. I know if I'm crap or not." Sophie followed by stating - "Me neither, cause l'm like, always really harsh on myself." These results identified that students took an honest approach in self-evaluation but found it difficult to give the same level of honesty in peer evaluation.

At the second focus group (FG2) the participants were asked - "How well do you feel you are able to evaluate yourself and how do you think it works giving feedback to other students?" Debbie stated - "I wouldn't feel weird giving people tips for performing and stagecraft cause I know there are some things I'm good at. When it comes to vocals I don't think I'm good enough to tell people what to do when I don't know what the hell I am doing myself." Sophie also felt there were only certain things she could feedback on because of her own limitations. She said - "Like I don't really have the qualification or anything. I feel kind of weird, like, I don't know." These findings strongly supported the research of Latukefu's (2010). These findings showed that peer evaluations were made if the individual felt confident in their own ability. However, if the student was not confident they did not consider their feedback to be appropriate.

The skills test assessment - term one and term three

The first summative test revealed distinctive differences in relation to students application to the designated workbooks. The students' who 
documented their work and followed the workbooks were successful in producing a grade suited to their academic ability. In the first skills test, Luke achieved a good grade considering he had had no prior experience with singing training. As mentioned earlier, he was in his final year of the applied degree programme and had chosen singing as a second option. He had been an advocate for the deliberate practice workbooks and had mentioned that all instrument study classes should use the same format. However, as the demands of Luke's study increased throughout the year he was unable to keep up with his vocal study commitments and he achieved $\mathrm{C}$ grade. If Luke had been able to continue with his study levels it would have been interesting to see whether his grade would have been higher than the other participants, who had studied singing in the previous year.

In contrast, the participants who refused to use the workbooks failed in their first attempt of the skills test and were given another opportunity to resubmit the assessment. If a resubmission was granted the students could only achieve a maximum of a $\mathrm{C}$ grade -Sophie, Pam and Debbie received a $\mathrm{C}$ grade due to the resubmission policy. The results of the second skills test were varied which was once again reflective of the students' application to vocal studies. At a late stage in term three the vocal coach encouraged Sophie and Debbie to study for the skill test as they were at risk of failure. Sophie and Debbie both managed to improve their subsequent skills test grade by applying themselves to study and subsequently avoided a resubmission or fail grade. However, Pam had to resubmit her work a second time and received once again a $\mathrm{C}$ grade. As mentioned earlier, Pam struggled with the musicianship which was not picked up by the vocal coach and consequently the appropriate measures were not taken to assist her in this area of study.

\section{Performance assessment}

The mid-year performance assessments results were generally higher than the end-of-year results. The students appeared to be more optimistic at 
the mid-year assessment as study demands were less taxing than at the end of the year. As part of the music course the students were required to participate in a musical production which was directed by academic music staff. This musical production required an increase in performance hours and a higher demand in their workload. It is important to note that during the third term the students' academic studies were not adjusted to accommodate the increase of the performance demands. Because of this extra workload students appeared to reach their peak level of performance and consequently regressed until the year ended. In other words, the demands of the musical production ended up all-consuming and left some of the students exhausted. And because of these factors some of the participants were unable to maintain this high level of performance which negatively impacted on their final performance assessment. From the researcher's memo notes - 'The issue of work overload in term three needed consideration as students did not receive any academic recognition for such efforts. It was also concerning that they appeared to be losing momentum which ultimately impacted on their final official performance assessment grade.' There will be further discussion on this finding in the following chapter.

Participants' overall summative results for 2011

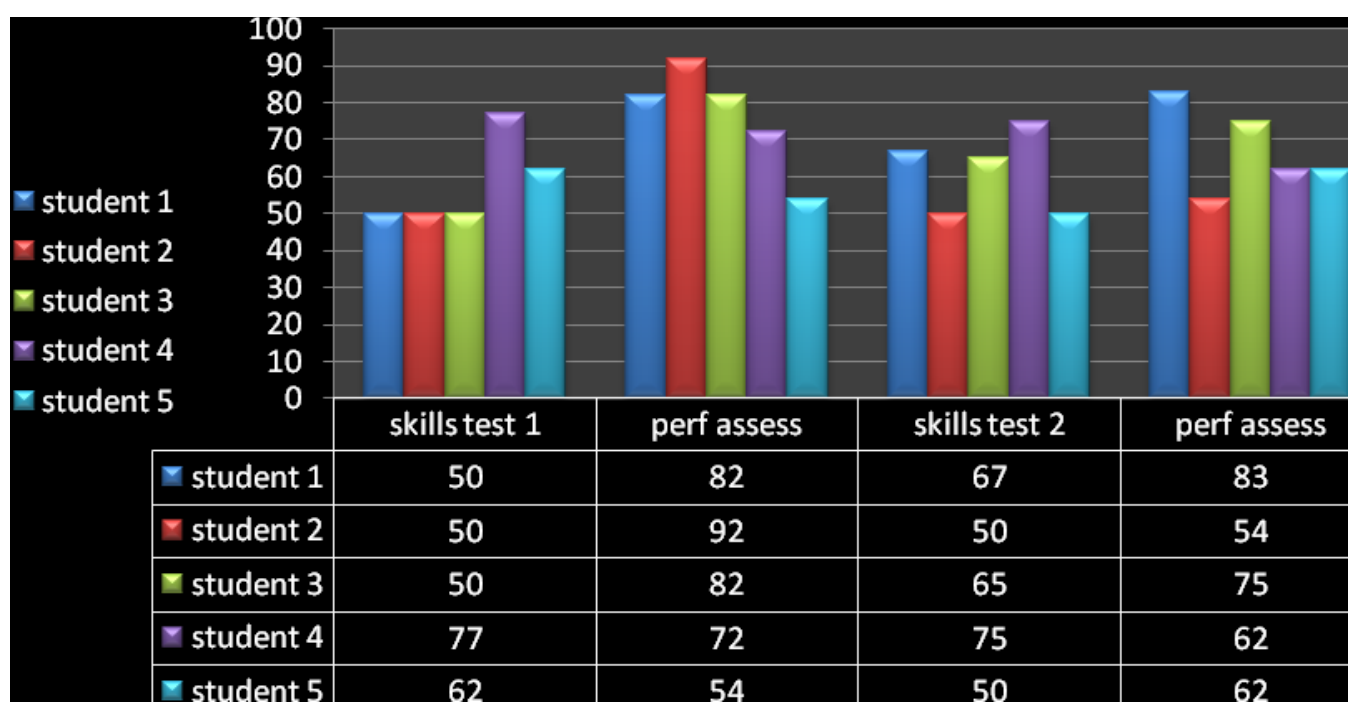




\section{Assessors' observational comments}

As mentioned in chapter three, the same panel of assessors graded the participants in both mid-year and end-of-year performance assessments. For the purpose of this present research, the assessors were required to fill out two different grading sheets. The first grading sheet was familiar to assessors and was based on a holistic approach - their 'gut feeling' and writing up their descriptors and the second grading sheet was a criteria specific grading method (appendix 2b).

When asked if there were any noticeable differences between the previous year level 5 students and the participating students an assessor gave the following comment - "To my mind, the standard of the top performers has been consistent across the two years." This comment suggested that the introduction of sport psychology methods may not have significantly changed the level of performance achievement. However, it is important to note that one of the limitations of this research project was the dynamic make-up of the group participating.

When the assessors were asked to comment on the criteria specific grading method it was suggested that the grading sheet was more precise in terms of song by song analysis of key areas of achievement for vocalists. The following comments were given - "Our existing marking system encourages a judgement of each criteria measured across the whole performance, and does not require individual results for each songs." One of the other assessors pointed out that - "...the criteria grading sheet was useful for those assessors who were not familiar with singing terminology..." and recommended a combination of holistic and specific criteria was developed for future marking. It was also suggested - "that the criteria specific grading method was less likely to define information for the student, were as the holistic method allowed for a more descriptive analytical approach giving students more informative feedback." It was also mentioned that filling in different grading sheets at the same time was challenging and interrupted their holistic ability to grade the performances. These findings supported the 
investigative reports of Stanley, Brooker and Gilbert (2002) and Saunders and Holahan's (1997).

\section{Performance assessment and group cohesion}

For the mid-year assessment Pam had chosen professional musicians and had expressed how difficult and stressful it was to try and arrange rehearsal times. The following comments from Pam's rehearsal journal -

The only downside with working with good musicians is that they are so busy and in hot demand, so getting them in for practice is hard work indeed. Fortunately, they had learnt their parts and were ready for the performance to play on my performance assessment.

However, the results indicated that by Pam working with professional musicians the level of group cohesion was strong and connected which was a contributory factor to the $92 \%$ pass rate she received. Pam also indicated that from this level of group cohesion she had been able to experience peak performance. She said - "I hit them during the year, but sometimes it's there, sometimes it's not. Like sometimes it depends on your band as well. Like, if they're all on it's like you hit your peak performance, but if they're not then it's like ugghhh." In contrast, Pam's end-of-year assessment produced overwhelming negative results due to excessively low group cohesion. As stated earlier, she was stressed trying to organise rehearsals with the professional musicians and chose inexperienced talented musicians for this performance. Rehearsal scheduling was easier as the musicians were music students from the music school's foundation class. The musicians were talented and when they rehearsed under the guidance of academic staff, performed remarkably proficiently, for the level of study. However, their inexperience had a devastating impact on Pam's performance assessment. She encountered a different level of stress and responsibility in comparison to mid-year - "I feel under-rehearsed and feel like l'm putting a whole lot of pressure on my band to help me pass". This will be discussed in the following chapter. 


\section{CHAPTER FIVE \\ DISCUSSION AND CONCLUSION}

\section{Introduction}

This study examined the impact a sport psychology based training programme had on a cohort of contemporary singing students. The first part of the discussion is the singing students' response to the deliberate practice workbook and their practice routine. To begin with, the students' response to the idea of deliberate practice training was positive. This initial reaction was short-lived by some of the participants and was replaced with non-compliance and resistance while others found the workbook useful.

\section{Deliberate Practice}

Individual's educational and deliberate practice history

An issue that was found amongst the participants was their limited hand writing ability. This finding was supportive of Matthew's handwritten work and his comment - "I hate the workbook" suggested that hand-written work was problematic for him. Marchant's (2000) discussion referred to an individual's educational history and how it is possible for resistance and noncompliance to interfere with study. Other contributory reasons were similar to those identified by Ericsson et al. (1993) and Jorgensen (2002). They suggested that an individual's past quantity of deliberate practice is directly related to the individual's current practice habits.

As most of the participants had had no previous formal singing training they were not familiar with practice methods. Ericsson and Jorgensen pointed 
out that initial practice usually starts with parents who assist children in keeping a regular practice schedule and point out the value of practice for performance achievement. It is only as the individual becomes more involved in the activity that self-directed motivation aspects are seen to develop and practice becomes closely connected to the individual's goal; deliberate practice starts slowly and increases over time. These results could suggest that the participants' starting age hindered deliberate practice application. It would be fair to assume that the students who have had no previous experience were more likely to avoid practice because of practice inexperience. As deliberate practice starts slowly and progressively over a long period of time, it may be unreasonable to expect students to engage in the suggested deliberate training method. Therefore it is recommended that the vocal programme be re-evaluated and adapted to an appropriate level giving consideration to students' prior education and practice knowledge while still ensuring progressive training outcomes.

\section{Students' perception of practice}

The students' perception of the workbook also seemed to cause practice disengagement. Sophie mentioned - "I am not a journal-keeper, I practice songs." Her personal focus to singing training was performance skill based which meant Sophie was only practising songs for up-and-coming performances. Her perception of practice was also found among the other students. They did not seem to understand the concept of training both physical and psychological aspects of singing. This meant that the students were focused only on performance skills and skill acquisition development was omitted. Without the balance of both physical and psychological attributes it was unlikely progressive development would occur. In Moore's (2010) view, a balance of physical and psychological aspects of training must be implemented if progressive development is to take place. He suggests that a 'trusting mindset' must be adhered to and recommends that initial 
training is dedicated to $80 \%$ skill acquisition and the other $20 \%$ developing performance skills.

However, closer to the performance event, Moore considers that these percentages are changed around which allows for $80 \%$ on performance factors and $20 \%$ on skill acquisition. He also noted that practising to perform is not the same as practising to improve skill acquisition and without deliberate practice on skill acquisition it is unlikely an individual will improve in performance achievement.

In this study the students were exercising the performance aspects of Moore's suggested formula and did not seem to identify the relevance of vocal technique development. Although they performed extensively throughout the year, their performance skills remained at a similar level. These findings support Ericsson and Lehman's (1996) view - "As for expertise, the levels of performance individuals attain after years of experience alone are much lower than those of experts who have adhered to regimens of careful training and practice" (p. 297).

To conclude, the students' practice was performance based and their focus was primarily on the performance aspects of practice. It is fair to say that without the application of deliberate practice, the participants did not significantly improve their vocal ability. It was noted that their singing ability either stayed at a similar level or in some cases declined in performance achievement.

\section{The relationship between the vocal coach/singing students}

In the first semester the researcher insisted on students using the workbook as it contained the vocal programme. The reason for this insistence was that all assessments were designed into the workbook which meant those students who were not following the workbook were missing out on important information aligned to the assessment. As the students' non- 
compliance strengthened, insisting on the workbook proved non-productive for both parties and the continued use of the workbook was re-evaluated.

Ravizza (1990) advised athletic coaches to consider operating standards, and referred to the concept of flexibility and being able to adjust to a situation. He states, "In every situation there is an ideal way to do your job, and then there is reality" (1990, p.331). On reviewing the situation, Ravizza's 'concept of flexibility' was seen as a favourable approach in the context of this study and modifications were made with the intention of improving student engagement. In an effort to improve the students learning engagement, the vocal coach encouraged students to individualize their singing programme, which in hindsight, was not necessarily supported by good educational practice. In fact, these modifications presented as a high risk of relative information being ignored and impacting negatively on the participants' final qualification result. Although autonomy is desirable in sport, education and music this present study identified the risks between autonomy and educational requirements. It is therefore recommended that caution and good educational practices are observed in such a process.

\section{Programme delivery}

From the results it was surprising to discover the students' extreme level of dismissal of strategic training. The intent of this programme was to improve programme delivery with informative and clear guidelines. Kostka's (2002) believes that ineffective practice is the result of teachers' assumptions of students' understanding of engaging in deliberate practice. Lehmann and Davidson (2002) also state that optimized practice is achieved when an educator implements a self-guided system that supports effective practice. Lehmann and Davidson's (2006) also reviewed factors that did not produce progressive results while undertaking deliberate practice. They believed the reason for such outcomes was due to suboptimal quality of practice. For deliberate practice application to be successful they found an individual required a high level of deliberate practice knowledge. 
However, the findings from this study do not support the findings of Kostka (2002) or Lehmann and Davidson (2002). In this study, the students received appropriate information and guidelines associated with deliberate practice. These results suggested that practice application knowledge is only one aspect in relation to practice engagement. It cannot be assumed that the educator's programme content had inadequate information on deliberate practice engagement. Although the students were given detailed information in this study, there was no evidence that self-directed application was developed through adequate information. When the students were asked at the $2^{\text {nd }}$ focus group (FG2) whether or not they had a regular practice routine, they all indicated that they did not practice. Debbie said - "Yeah, I don't think any of us do." And Pam stated - "Nuh, I can't be arsed". Matthew reiterates - "Um...not very often... practice is just really listening to the songs." Therefore, it can be concluded that adequate information and discussion is only one aspect of deliberate practice engagement and a more in-depth evaluation of students' practice engagement is required and recommended.

From the literature reviewed there was no research that examined the practice habits of contemporary singers which has made this project a worthwhile endeavour. Further discussion and investigation would be worthwhile in view of the students' educational background and what impact this is having on their learning outcomes.

No practice routine

By the end of the academic year all of the participants had discontinued using the workbook and were not applying progressive training methodology to improve performance or develop their vocal ability. In view of the students' reluctance to use deliberate practice it was important to examine the attitudes and practice habits of recognised singer/songwriters from the New Zealand contemporary music industry. The writings of Chapman (2010) shed some light on the attitudes and aspirations of the New Zealand contemporary singer which at times reflected the attitudes of the students in 
this singing programme. One that was of particular interest in view of Sophie's case was that of Julia Deans a songwriter/singer for the bands 'Fur Patrol and Banshee Reel'. Julia studied at the Wellington, Massey Conservatorium, Jazz department, but dropped out to join a working band. Her comments - "this was endlessly more exciting, and immediately far more educational for me, than trudging up the hill to sit in more boring theory classes and study weird chords and scales - for which I have never had the patience." (p.154). It appears Julia was at the jazz conservatorium biding time for such an opportunity - the same could have been said for a number of students and in particular Sophie.

\section{Music theory}

A concerning emergent result was the students' lack of knowledge and application of music theory. The summative results indicated that the level of musicianship was unsatisfactory for the level of study. Generally the students found this topic extremely challenging and mentioned that it may not be appropriate for vocal studies. Luke, for example, who had previously studied guitar, felt that musicianship theory should not be included in the programme due to limited contact time. He had personally found the singing course difficult and the additional study of musicianship skills made the vocal programme too intensive. In contrast Sophie felt that the musicianship component in the singing course was of value, and necessary for singers when working with a band. What must be addressed at this point of the discussion is the individual's ineffective practice. If students had seriously committed themselves to developing their musician theory it is possible that this component would not have caused them such an issue. Musicianship is an essential component to being a professional singer and without understanding the necessary musical vocabulary, singers are left totally reliant on other musicians for their musical direction. For a singer to be respected, in their own right, it is essential that they are empowered to discuss musical ideas and take musical direction when necessary (Peckham, 
2000). The students' inadequate musical knowledge was of serious concern and resulted with the introduction of compulsory keyboard lessons commencing in 2012. Future investigation will disclose whether the students' inability to apply music theory was a substantiate reason for ineffective deliberate practice behaviour.

\section{Performance requirements already attainable}

The issue of natural talent and deliberate practice obligations was of interest in this project. The main pre-requisites for students' entry to this level 5 vocal study paper is their natural vocal ability and completion of the previous level 4 papers or equivalent. The assessments results showed that the participants were in fact producing high grades in their performance assessments, even though they were not engaging in deliberate practice. If the students were able to achieve high grades in performance achievement, without the engagement of deliberate practice, then it is understandable that practice would be perceived by them as pointless. However, in Colvin's (2008) view, natural talent is not enough if peak performance is to be attained. He believes the following view is not supported in research - "most people simply know that certain lucky individuals are born with a talent for music, and that's the main factor in how well they perform it or write it" (p. 17). Colvin comments on research conducted in the UK suggests that deliberate practice was the major contributor to excellence and not natural talent. All subjects in his research were found to be: (1) self-regulatory learners and (2) had long hours of deliberate practice engagement and (3) the average starting age was eight years old. As one of the researchers, Professor John A. Sloboda of the University of Keele, put it: “There is absolutely no evidence of a 'fast track' for high achievers." (p.19). Nevertheless, this discussion proved difficult as natural talent and deliberate practice associated with contemporary music exposed a significant gap in the literature. 
Empirical findings would suggest that the participants' view practice as learning necessary repertoire which Moore (2010) refers to as performance training. It seemed that all other aspects of progressive training were irrelevant and unnecessary - as Sophie said "I just do it." If students are relying solely on their natural talent they are in danger of limiting their opportunities in the music industry. To achieve a professional standard a high level of deliberate practice is essential - talent is not enough. In view of this result, it is important that the vocal programme is aligned with the music industry and students are given considerable opportunity to meet professional singers and musicians in this educational setting - workshops. These types of workshops could motivate singers to improve their own singing skills by practicing. This is supported by Beltman (2005) who found that observation of other successful athletes and musicians motivated individuals to higher levels of practice. The interaction between the students and successful singers/musicians could close the gap between the education environment and 'tough' music industry. It is also proposed that an investigation on the attitudes and practice habits of professional contemporary singers is undertaken. This type of feedback would advise educators on how to approach progressive training while embracing aspects necessary for the music industry.

Natural talent and performance achievement decline

Debbie and Matthew's response to deliberate practice was particularly supportive of Ericsson's theory (2006). These students were natural performers and demonstrated good vocal skills in both pop/rock genres. Their application to deliberate practice was minimal and practice was only applied for the purpose of learning necessary repertoire for up-and-coming performances. As Matthew said - "I only practice songs". A strategic progressive focus was not applied to their voice training and by the end of the year both of the students' performance achievement levels had declined. 
A key to progressive training requires specific training which will challenge skill acquisition and prevent arrested development associated with automaticity. Ericsson and Lehman (1996) believe that many individuals stay at the same performance level, even after years of experience because they have not adhered to regimens of careful training and practice. Lynch's (2001) writings also indicated that athletes' did not engage in progressive training because they were content to stay at their present level. He considered that athletes were not prepared to align themselves with the level of discipline required to achieve a high level of performance. In this musical environment, it seems that Matthew and Debbie were content with their level of skill and were not prepared to push themselves to a high level of performance achievement. It is proposed that the stakes in this programme may not seem reason enough to increase skill proficiency and therefore, give no substantial rationale to pursue excellence.

Deliberate practice and the environment

An emergent theme was the environmental context and its effect on deliberate practice engagement. The findings from this study indicate that some students experienced performance anxiety during practice and were not prepared to practice unless the environment was private and soundproof. This finding was not surprising to the researcher as this was commonly noted from previous years of teaching in this singing level. The student's vulnerability to the environment was a concern and needed further consideration. The findings indicate a number of reasons which were contributory to the students' response to deliberate practice; (1) inexperience, (2) understanding practice methods, (3) lack of resources and (4) abilityapproach goals. Despite these reported barriers, the issue of practice engagement needs consideration and forethought to find a way forward to engage students in practice methods. The inadequate level of deliberate practice is resulting in students not being adequately prepared for a career in the music industry. 
1. Inexperience - from the memo notes it was suggested that if students had not previously engaged in formal practice they may not know how to practice or perceive its relevance. As mentioned earlier, some participants had had no formal vocal tuition in early childhood. In view of Bloom's (1985) research, he studied elite performers from both the sport and music domain and found that they had all started developing their chosen activity, from early childhood. Bloom's research is also supported by the autobiographies of world-class tennis player Andre Agassi (2009) and the Formula One racing car driver Lewis Hamilton (2007). Both Andre and Lewis write on the intensive training they received during their childhood and in both cases it was their fathers' obsessive passion for world-class excellence that seemed to influence the making of such world-class sportsmen. It is important to note that no literature on early formative training for contemporary singers' was found. However, if Bloom and other researchers are correct in their analysis it is possible that without contemporary singers starting training in their formative years it is unlikely they will engage in the demands of deliberate practice. If this proves to be the case then other practice methods and knowledge need to be sourced from other educational domains. As this educational setting is a tertiary level, understanding of adult teaching methods and engagement would be advisable. The educator would require a broad knowledge on how to incorporate practice into the vocal programme considering factors such as the students' age, gender, cultural and the educational environment.

2. Understanding practice methods - As mentioned earlier, Jorgensen (2002) also consider that a person's starting age and the quality of past practice and development will impact practice. He believes that educators in higher education must not assume students' previous knowledge on practice methods and leave them to find their own maximum practice routines and strategies (2002). Lehmann and Davidson (2002) encouraged educators to develop a self-guided system that directed a developing musician to support efficient and quality practice. Sophie's statement "I just do it" was the general 
response of the students and practice. In this study, the educator did not assume that the participants would understand practice methods and so provided a self-guided system workbook - a sample from the deliberate practice workbooks has been provided in appendix 4a. Although the vocal coach applied Lehmann and Davidson's recommendations, it was concluded that other factors must also interfere with practice behaviours. It would be a worthwhile endeavour to investigate the engagement of practice, in future research, which focuses on adult learning and deliberate practice engagement. If an individual has not had the opportunity to receive early childhood practice engagement in singing it should not be assumed that they were unable to reach their potential as a contender for the music industry. However, the starting age of singing training may well influence the singers' overall performance achievement.

3. Limited resources - Another issue of concern for both students and vocal coach was limited resources. Lehmann and Davidson (2006) acknowledge that inadequate resources can impair quality practice. The limited resources mentioned earlier were limited contact time with the vocal coach and appropriate soundproof practice space. As the students had expressed their vulnerability because of privacy, their noted performance anxiety may have outweighed the consequence of no practice. Although the limited resources were considered problematic, it was assumed that students would still practice for the purpose of academic achievement. It is therefore, recommended that informative notification of practice expectations and the challenges is given to future contemporary singers students entering this programme. This would allow the singer to consider and discuss these challenges before starting their academic journey.

Conversely, not all the participants struggled with performance anxiety associated with practice. Some found the environment beneficial. Luke's statement - "I don't mind doing that because after lessons, I feel more confidence when l'm singing." Matthew also found the environment a nonissue for practice. It is interesting to note that this issue could in fact be 
gender related. The female students were strongly affected with performance anxiety associated with practice while the male students had no apparent issue. While outside the parameters of this study, this is an area worthy of further research.

Ability-approach goals - The students' level of performance anxiety associated with public practice suggests that the students indirectly applied ability-approach goals. Nielsen (2008) found that achievement goal orientation during practice was more likely to be regulated by advanced music students, whereas less advanced students focused on ability-approach goals. Ability-approach goals imply that the student is more concerned with appearing more competent in front of peers. This study was reflective of Nielsen's findings and indicated that participants' were not yet at a professional/advanced level. In view of Nielsen's findings it could be concluded that once these students are at an advanced level of study their levels of anxiety associated with practice will begin to decrease and improve practice behaviours.

Finally, these results conclude that deliberate practice was not used consistently throughout the year by students which suggest other factors are contributory to deliberate practice engagement. However, as this research has found practice avoidance, it would be advised that other aspects of training interaction are sought from Lacaille et al. (2005) who identified the different goal approaches used by athletes and musicians when training for peak performance. They found that musicians' response to intrinsic goals associated with enjoyment were beneficial to performance/practice while mastery and performance approach goals were in fact detrimental to a musicians performance. This gives valuable insight into further programme development as it identifies the musicians/singers perspective, which implies that enjoyment is a key component to music expression and practice. The students were excited to start deliberate training and yet it appeared they lost their enjoyment and passion for singing. This is not the desired response for either educator or student and must be avoided so learning is not disrupted. 
Further investigation is required if deliberate practice and enjoyment are to be combined. To attain this combination, within this educational environment, the educator and students could benefit from both being involved in designing an individualized programme at the beginning of the academic year. The individualized programmes would need to be flexible for both students and educator to ensure that learning outcomes were attainable and realistic to the level of study.

\section{Self-efficacy}

Sport psychology training endorses the concept that the individual's mind plays a crucial function in developing peak performance. Self-efficacy beliefs determine how people feel, think, motivate themselves and behave. A strong sense of self-efficacy can enhance human accomplishments and performance ability. Leith (2008) believes that the combination of:

Self-confidence, optimism, and self-efficacy provide the recipe for your belief that - I can do this, and are successful regardless of the situation. This feeling is absolutely crucial for attaining your ultimate success in competitive sport (2008, pp. 19-20).

Self- efficacy - physical and psychological balance

In this study the students' physical and psychological levels of development were in most cases imbalanced, resulting in a variety of combinations. Either the students were (1) strong performers and needed to improve their vocal technique or (2) well developed vocally and need to work on their performance skills or (3) students were not competent either in their vocal or performance ability. The first group identified was supportive of Leith's (2008) comment 'I can do this, and are successful regardless of the situation' (p.19). Matthew and Debbie were particularly convincing 
performers, even though their vocal abilities were somewhat limited. They were so confident on stage that they were not negatively affected by their vocal limitations. Their performances were positively affected by their high levels of self-confidence.

However, on observing live and recorded performances, it was apparent that the second groups' physical and psychological imbalance did impact negatively on the overall performance outcomes. Sophie's technique and vocal ability was of a higher calibre than Debbie and Matthew. However, in a performance situation, Sophie's stage persona was less confident. Previous researchers have considered that an individual's sense of selfefficacy will be strongly influenced by performance history (Bong, 1999et al.; Moritz, Feltz, Fahrback, \& Marck, 2000). Debbie and Matthew had both performed in professional bands before entry to the music course. Debbie trained as a dancer in her formative years and Matthew started as a lead singer of a band in his early teens which he maintained during his vocal studies. Sophie, on the other hand, had only performed in public while undertaking her vocal studies. A comment made by an assessor in regard to her performance persona - "Sophie has been encouraged by us to become more outward focused in performance." She acknowledged - "I need to up my stage craft." Her limited performance history appeared to weaken her level of self-efficacy, even though her vocal ability was stronger than Matthew and Debbie. Matthew and Debbie's performance history seemed to enhance their level of self-confidence as they were both confident entertainers. However, Debbie and Matthew may find that if they continued to perform within their 'comfort zone' their self-confidence may eventually decline and jeopardize performance ability. Other factors associated with physical and psychological imbalance which could be aligned to Sophie was Loehr (1984). His suggestion that negative thinking can create excessive muscle tension and poor concentration was evident. Also her performances supported Bandura (1997) who found that individuals can be highly talented but because of self-doubt make poor use of their capabilities. 
Finally, the third group demonstrated a lower level of vocal and performance competency but a higher level of determination which seemed to enhance self-efficacy and personal success. Bandura (1977) considered selfefficacy beliefs determine how people feel, think, motivate themselves and behave. A strong sense of self-efficacy enhances human accomplishments and performance ability. An example of this was Luke's involvement in the vocal programme. His intent was to develop his vocal ability so he could sing his original songs, and not about being an excellent singer. This gave Luke the opportunity to build his vocal ability so he could perform his own music. As a result of this action Luke accomplished his singer/songwriter and performance skills. By the end of the year Luke had produced six of his original songs onto a CD and performed his music to the public and online audiences.

Self-efficacy and the social environment

Another result was the influence that the environment had on the students' confidence and performance achievement. In this educational setting it was evident that students were strongly influenced by their social environment which supported Marsh's 'big fish little pond effect' (BFLPE). This model proposes that people compare their abilities with the abilities of their peers and use this social comparison impression to formulate their own self-concepts (1984a). From the sports domain Marsh and Peart (1988) propose that BFLPE can cause a negative impact on performance achievement when an individual compares themselves to those in their social environment, and thus encouraged self-evaluation as a measure of success.

In this study, observational evidence suggests that BFLPE contributed to the students' level of self-confidence and belief when they analysed their own performance achievement. A result that was of particular interest, in view of BFLPE, was the response of some students after the first performance assessment. These students were convinced that their official grade was lower than their expectations and they challenged the official mark. From 
discussions initiated by the individual students, they were convinced their performances were better than their peers and could not understand why they had received a similar grade. The students' comments reflected their perception of themselves amongst their peers. However, once the students had personally evaluated their performance from a video recording, using a 'specific criteria grading sheet' (appendix 2b), the same the assessors used, they accepted the official grade as appropriate and correct which supports Marsh's BFLPE model.

In this social environment the danger proposed by BFLPE was the potential for students to have unrealistic expectations of music industry demands. A major focus of this vocal course was to ensure students were individually prepared for the music industry. Because of BFLPE associated with this study, students were often reminded that comparing themselves with their peers could give them a false sense of reality. They were encouraged to self-evaluate and continually focus on their own performance efforts. To avoid a high level of BFLPE an increase in performance opportunities were provided within professional working performance environments. This was to encourage students to connect in a realistic way to the music industry and not be totally absorbed in the music educational environment.

\section{Self-efficacy and preparedness}

According to DeVenzio (1997) high levels of self-efficacy in performance reflect athlete's preparedness for an event will impact on performance achievement and states - "confidence level mirrors skill level" (p. 91). In the mid-term assessment Pam had performed with professional musicians which enabled her to achieve $92 \%$ the highest grade, of all the participants; boosting her self-confidence. However, Pam felt the preparation required for this performance had been extremely difficult. The musicians were often unavailable for rehearsals because of other musical commitments. For the end-of-year assessment Pam chose inexperienced, talented musicians from the music courses foundational level. Her personal preparation and in-put 
into this performance was extensive and even more stressful as the inexperienced musicians had to rely on her musical direction, which was limited. The end results were devastating for Pam and her grade dropped from $92 \%$ to $54 \%$. Despite working harder than the previous performance assessment, she had scored a much lower grade. In this situation DeVenzio's (1997) statement 'confidence levels mirrors skill level' (p.91) was only applicable to the mid-year assessment. Pam's level of self-efficacy did not change but the performance environment momentarily altered her selfconfidence. At the end-of-year performance assessment Pam was unable to perform at her level of expertise as she was surrounded by inexperience and musical error. Although she was extremely disappointed in the grade there was no evidence to suggest that the experience had permanently damaged her self-confidence. She was experienced enough to appreciate that it was the environment that interrupted her performance achievement and not her performance ability. It is therefore feasible that uncontrollable factors such as group cohesion can momentarily impact on one's confidence. Although Pam's self-confidence and personal preparation was high, she was affected by uncontrollable factors in the musical environment and paid a high price. In other words, it would seem that group cohesion is only as strong as the collective and each individual has the potential to impair or be impaired by the performance of others.

\section{Self-efficacy - vocal coach/singers relationship}

In the sport domain, coach/athletes relationship is seen to have a major impact on performance achievement. In educational domain, the teacher/student relationship is also seen to have an immense influence on self-efficacy and the individuals' progressive learning outcomes. In this educational setting, the results showed that the relationship between the vocal coach/singer was also relevant and influential on self-efficacy, performance achievements and learning outcomes. In this present study, it was extremely challenging for the vocal coach and students to develop a positive relationship 
because of the limited contact time. Sophie expressed this issue in FG1 in the following statement:

"It's not enough time to build a relationship with the tutor if it's the first time you've been around as well. I remember the first year I came here and I was just, I didn't relate to her. I didn't connect with her until about the end of the year. You don't feel that building of relationship which is so important." Debbie also found that the limited contact time interfered with her learning. She said at FG2 - "Like we are all actually working in a process of working. Unfortunately, half an hour a week, I think it's ridiculous. It's ridiculous. It's just not enough. What about trying to have one hour?"

In building such a relationship consideration must be given to environmental factors. According to Bandura (1997) and Loehr (1984) developing a relationship based on autonomy, where both the coach and athlete feel supported, a higher level of performance achievement was found which they believe reflected this working relationship. However, if a coach is harsh and dominates the coach/athlete relationship, it can impact negatively on an athlete's self-confidence. Such a negative impact can ultimately disrupt their self-confidence to such a level that it causes a decline in performance acquisition (Bandura, 1997; Loehr, 1984). In the development of this present research, the vocal coach's intent was to encourage an autonomy relationship through the implementation of deliberate practice which would encourage discussion and progressive training. The limited contact time and the implementation of these new concepts seemed to interrupt the development of this relationship. Not only were the students struggling with the new training programme but it also had an effect on the self-confidence of the vocal coach. The students' resistance toward the programme was challenging and caused the vocal coach to doubt the wisdom of introducing a sport psychology based training programme. However, if the implementation of the programme was taken over a longer period - two years - it is possible that the relationship between student/vocal coach would improve and also overall academic results. 
One disturbing aspect was identified by a comment from Debbie stating "she would care for her best students and not care for others." Although this was not the intention of the vocal coach, it was important to respond immediately and ensure professional self-reflective measures were taken. This situation had the potential to significantly interrupt Debbie's learning and performance achievements. Navin and Egan (2011) reflected on effective coaching and suggested that training methods are challenging yet achievable, and as a result they should serve to raise the person's self-esteem. The challenge for the vocal coach, in Debbie's case, was her practice avoidance. Lacaille, et al. (2005) findings indicated that musicians' performance acquisition was reflective of the level of enjoyment they experienced, whereas, athletes used mastery and performance approach goals to ensure high stand performance. Lynch (2001) also found athletes with excellent potential for world-class standards did not pursue the required level of excellence because of the high demands. They were content to play at their level of expertise without sacrificing their personal lives. As mentioned earlier, Debbie seemed content with her level of vocal ability and did not place the same emphasis on practice as her vocal tutor, hence the potential for conflicting interests and expectations.

The results in this study suggest that self-efficacy is an influential factor of performance achievement and further consideration was needed on how to foster a good student/vocal coach relationship. Kidman (2001) suggests that coaches use an empowering style of coaching where athletes gain and take ownership of knowledge, development and decision making to help maximise their performance. This style of coaching could be adapted to this vocal programme to encourage autonomy and student engagement. If Debbie had felt empowered she would more likely have communicated her situation earlier which would have encouraged a quicker response from the vocal coach. It is also advisable that the vocal coach adapts a holistic approach to teaching which promotes individualization. This type of training programme would meet the needs of each individual singer and allow for an individually 
tailored programme which could enable an empowered style coaching approach to singing.

\section{Motivation}

One area of interest in this study was to identify whether motivational mechanisms increased deliberate practice. The results identified that by the end of the academic year none of the participants had a regular deliberate practice routine. This suggested that motivation mechanisms did not influence deliberate practice. However, the results suggest that the participants were in search of extrinsic motivational mechanisms. From the sport domain, Hodge's (2004) strongly suggested that intrinsic motivation allows an individual to succeed more than other motivational factors. In Hodge's view, extrinsic motivation was less likely to have a lasting effect (2004). From the music domain, Martin and Cutler (2002) linked 'flow' to intrinsic motivation and suggested that musicians must sustain positive motivation over time in the face of failure and disappointment. However, in this study there was evidence to suggest that the students favoured extrinsic over intrinsic motivators.

\section{Extrinsic motivation}

The need for extrinsic motivation was indicated earlier in the students' feedback concerning the limited contact time they had with their vocal coach. In the sport domain, athletes' strongly rely on the professional expertise of their coach to analysis training/performance and give constructive feedback.

An extensive part of the course in this study included band workshops which the students considered an excellent educational environment in which they could acquire voice and performance direction from their vocal coach. It seemed, however, that the students were decidedly dependent on the vocal tutor for support and direction. Their feedback indicated that the allocated half an hour weekly lesson was inadequate and they felt the vocal tutor should attend band workshops and all public performances. It is fair to say, that the 
students were not self-directed or confident in their skill acquisition and were yet to establish self-directed monitoring. As mentioned earlier, this level of study is perhaps a contributory factor to students' motivation mechanism. The students' dependent behaviour seemed to favour extrinsic motivators and self-directed learning was yet to be established. With an educational environment that encouraged autonomy, empowered by extrinsic motivational, the students' intrinsic motivational levels could benefit. However, empirical knowledge would suggest that as these students advance in their vocal studies, self-regulatory learning (SRL) attributes are more likely to emerge and encourage learning engagement.

The use of extrinsic motivational methods was supported by Beltman (2005) who examined motivational aspects associated with elite athletes and musicians. She found that extrinsic motivation was sought after by elite performers to enhance their intrinsic motivation. The results of this study suggested the application of external motivators were predominately used by the students. Sophie did not appreciate being told how to practice and was convinced that observation of others and emulation was what she personally required and that the rest of her study was irrelevant. She obviously loved singing and deliberate training seemed to get in the way of her passion and turned it into unnecessary hard work. Sophie did not change her stance on this and continued this way throughout the entire academic year. As mentioned earlier, the vocal coach decided to take a flexible approach and encouraged her to be open and communicate her preference of task at lessons. However, this was a difficult task for the vocal coach and at times frustrating as there seemed to be no ground for compromise and Sophie risked not completing the academic requirements.

As Aria (1997) stated, it is important that students are guided in the learning process and are encouraged in (1) self-awareness, (2) connecting and learning, (3) taking action, and (4) contributing to their own learning. In reference to connecting and learning the coach's role was to provide support, mentor and act as an information source so that individuals began to expand 
their choices and opportunities. Csikszentmihalyi et al., (1993) research suggests that only a minority of talented individuals respond to the need to increase effort and commitment to develop their talent.

Sophie was one student who, while naturally talented, did not see the relevance in deliberate practice as her level of vocal ability, was in her opinion, sufficient to get her through the vocal course. In Sophie's case, extrinsic motivation was all she required and increasing the level of effort was considered unnecessary. These results suggest that when Sophie was not challenged or progressive tasks and effort were not applied intrinsic motivational mechanisms were at risk of being impaired or subsided. This was also strongly evident in the cases of Debbie, and Matthew who appeared to rely on their natural ability and performance history. These students did not extend their vocal ability by taking action and contributing to their own learning. In Hodge's (2004) view intrinsic motivation is favourable in progressive training whereas extrinsic motivation is less likely to be effective. $\mathrm{He}$ also considered that motivation is essential to psychological training if consistent success is to be achieved and sustained. Further understanding of intrinsic and motivational mechanisms is needed in this vocal programme as most of the students were not motivated to practice or attentively pursue a higher level of singing proficiency.

\section{Intrinsic motivation}

The students offered a variety of perspectives on the importance of how motivation can affect one's engagement. On viewing Debbie's performances on both live and video recordings she was a strong competent entertainer. Nevertheless, Debbie's lack of personal commitment to her vocal studies disrupted her personal vision because of her disengagement with her vocal studies. As mentioned earlier in this chapter, Debbie's stage crafting ability was confident but she could only sing in her 'comfort zone' - Debbie's vocal range was limited. It is important to reiterate that Debbie did not practice which resulted in a decline in her end-of-year performance assessment 
results. However, Debbie saw herself differently and felt she had vocally improved throughout the year. In Hodge (2004) view, intrinsic motivation is essential if an individual is to reach excellence. Debbie's intrinsic motivational mechanism did not encourage her to practice and consequently she did not achieve excellence. Lynch (2001) suggests that some individuals are content with their skill level and refuse to sacrifice their personal lives in order to achieve their full potential. Therefore, it could be suggested that intrinsic motivation appears to be influenced by what level of performance and skill acquisition are perceived as satisfactory by the individual.

Although it seemed student self-development was unsatisfactory because of inadequate practice, comments from some of the students suggested that they were showing signs of independent learning (SRL). Sophie said - "I've noticed that, some vocalist, you know, they'll do the same; they'll do at least one song from the same artist each performance assessment. And just too like, get people to sort of step out of their comfort zone." Pam's final comment at the FG2 - "We need to motivate ourselves too. Like, or it get too boring." As mentioned earlier, the level of study may have strongly influenced the students' motivation mechanisms. Although the question was directed at deliberate practice, the students were starting to discuss their responsibility toward performance achievements.

Acknowledging that this particular level of study has been challenging and disappointing in regard to students practice efforts, it is worth noting that the emerging of these motivational changes could encourage self-regulatory aspects and potentially liberate students practice behaviours. As Hodge and Leith $(2004 ; 2008)$ suggest, intrinsic motivation is the most favourable and the most effective motivation for successful performance achievement which are also recognised aptitudes of a self-directed learner. 


\section{Goal setting}

In the sport domain, goal setting orientation is acknowledged as vital in producing optimal performances. The purpose for introducing goal setting as part of this programme was to increase performance ability and outcomes which would encourage students to continually push themselves to their maximum ability. Rabasca (as cited in Kornspan, 2009) commented that athletes often set goals which are not specific or realistic and are deemed unfavourable to performance outcomes. A well designed acronym by Kirschenbaum (1997) SMART (S)pecific, (M)easurable, (A)chieveable, $(R)$ ealistic and $(T) i m e$ phased was referred to as an appropriate method in assisting athletes set effective goals and was introduced as a goal setting method for the purpose of this study. On reviewing the students' deliberate practice workbooks their lack of understanding and knowledge of goals setting became evident. Matthew, for example, set one long term goal to organise and perform in an originals band yet took no action to pursue the goals progression. As Rabasca pointed out, if goals are not specific or attainable it is unlikely the individual will achieve the foreseen outcome.

In contrast, Pam set short and medium goals for the purpose of deliberate practice. These goals were identifiable as process goals which are favourable to performance achievement. Although Pam had a good understanding on goal setting application her inconsistency in practicing was apparent and therefore the degree of development was limited. Leith (2008) suggests that process and performance goals must be appropriately executed otherwise they are pointless. In this case, it appeared that the balances of process and performance goals were effective and produced desirable results when applied. However, these results were only sustainable while Pam was implementing appropriate goal methods.

Another approach to goal setting was shown by Sophie who said that "I kind of just set goals in my head anyway, if you know what I mean, like I remember performances from last year and then I reflect back and I see what I'm doing now. And yeah, I just don't write it down." Marchant (2000) refers to 
athletes' non-compliance to goal setting as a 'red flag' that should not be ignored. He believes the reason for such resistance is because of the individuals' insufficient knowledge and understanding of goal setting processes. He also mentions how an athletes' academic standard can influence resistance. If the individuals' academic ability is limited, especially in written work, he believes the individual may see goal setting as homework and this may remind them of negative memories of school days, or it may be seen as a further infringement on their already busy lives. The overall response to applying goal setting methods was extremely limited amongst all the participants. This could suggest that the students did not seem to understand or see the relevance for goal setting in singing training.

The researcher's memo notes reported on the inconsistency and frustration of trying to establish methods of goal setting for the students. For example the comment was made by the researcher earlier in the year - "it has been challenging trying to motivate these students to use the SMART goal setting formula independently. I have encouraged students to write down goals while they are in their individual lessons." From the memo notes months later the frustration was still obvious as no student had used recommended goal setting. As the implementation of goal setting had not gone according to plan it was worth examining the approach of other coach/instructors in encouraging goal setting methodology. Ravizza (1990) talked about operating stands, and referred to the concept of flexibility and being able to adjust to a situation. He stated, "In every situation there is an ideal way to do your job, and then there is reality" (p.331). For goal setting processes to be successful the coach must take responsibility to ensure goals are reinforced constantly otherwise they cannot be successful (1990). Marchant (2000) also recommended that educators be attuned to the individual's situation and help adjust goals when necessary due to change of circumstances. He believes an open, trustworthy, and mutually respectful working agreement must be held between parties if goal setting is to work (2000). To improve communication and programme delivery the above factors are worth consideration for the future of this programme. 


\section{Performance}

A surprising result was the students' perspective on peak performance experience. The findings suggested that some students felt that they had achieved a peak performance experience from the level of emotion they had experienced while performing. What the students appear to have identified is the experience of flow described by Cskiszentmihalyi (1975). He concluded that flow was a human state of enjoyment which was experienced during an activity. In later research Cskiszentmihalyi and Jackson (1999) defined flow response as a "holistic response" or an optimal state of one's self, in harmony and total involvement in the experience. In other words, the mind and body work together effortlessly throughout the activity. The results from this study result would suggest that some of the singers were sensing a state of flow while performing. When the participants were asked if they had experienced peak performance sometime in the year Sophie and Debbie both considered that they had. Their feedback suggested that the experience was extremely positive. However, from observational evidence - video recordings - there was no indication that either student had reached such a high standard of performance that it could be considered a peak performance achievement. This is supported by Ravizza (1984) and Jackson (1992) who felt that peak performances are rare and in most cases produced by the elite athlete/performer. At this level of study it is unlikely a student would experience peak performance unless innate talent, group cohesion and environmental excellence were contributory factors.

Wrigley's (2005) research suggested that the examination environment was not conducive for peak performance. He indicated that the performance assessment environment is too stressful and has the potential to negatively impact on a performance. It was found that students were often reserved and insecure with the additional disruption of having to read music and needing to watch for musical direction. Because of these factors the performance standard was often less favourable. However, another contributory factor was the difference of opinion amongst the assessing panel. An example of this was an assessment of one of the participants and the 
different perspectives suggested by the assessors. One of the assessors felt the student was 'right in the zone' from the beginning of their first song, displaying a mood and creating a vibe that they were emotionally into the song and right in touch with what they were singing about. Conversely, on viewing the same performance assessment the additional judge perceived the students' performance as evasive and appeared totally self-conscious and nervous. The judge remarked on the students' vocal competency but did not sense a state of peak performance. These results implied that the assessors' perception of analysing peak performance was influenced by their own observation and emotional connection to the performance. This would also affirm that peak performance itself is subject to subjectivity which aligns with Mills (1991) - "Human subjectivity should be celebrated as it is the right of human beings to assess human" (p.176). In this study, the assessors' perception on analysing peak performance was subjective and therefore a challenging discussion to elucidate. It is worth noting that even though the assessors' subjectivity resulted in totally different analytic views assessing human achievement is a valuable task worth celebrating.

The participants' feedback also suggested that personal 'flow' experience was more likely to take place in a professional/public environment. In some cases their level of preparedness contributed positively to selfconfidence which promoted the 'flow' experience. As mentioned earlier, Devenzio (1997) states - "confidence level mirrors skill level" (p. 91) and for some of the participants preparedness most certainly gave them the confidence to perform at their best. It was not only the confidence they felt in themselves that gave this impression but also reflective confidence given by all musicians in the performance situation. These findings suggested that 'flow' could be manipulated by the musical environment and group cohesion (the band) which suggested that both internal and external factors are stimuli to 'flow' experience. 
The participants' interaction with the audience also seemed to influence 'flow' experience. Some of the participants felt strongly that the audience influenced their quality of performance. Debbie stated that "there's nothing better than playing in front of a responding audience." It was concluded that the audiences' level of emotional interaction with the performer influenced the performer's level of skill acquisition, by way of motivation, which seemed to enhance the overall performance outcome. It was also obvious in performance when the students' engaged the audience to a high level of enthusiasm. The result suggested that the rapport between performer and audience has the potential to either motivate 'flow' or peak performance or impair the performance outcome.

\section{Group cohesion}

As mentioned earlier, the students worked with the same musicians which gave the bands opportunity to develop secure group dynamics. As the bands/singer worked together for a year it was worth observing the development of band/singer team cohesion. This development was aligned with the phases of Tuckman's (1965) team development framework (1) forming, (2) storming, (3) norming, (4) performing and (5) adjourning and transforming. In this study it was noted that band performances were of a higher standard when students continued to work within the same group compared to when students were in a band for a short length of time. This was particularly noticeable when students were preparing for their performance assessments. Changing bands would significantly interrupt the band cycle and only allow the early stages of team development, such as the, 'storming' level. In view of Tuckman's theory the stages of team development play an essential role in performance achievement standards. An observation made in this study was that the students' performances were generally of a higher standard when they worked continuously with the same band. 


\section{Self and peer evaluation relating to performance}

Self and peer evaluation gave the students an opportunity to develop critical analysis skills. This study supported Lebler's (2006; 2008a) findings in self-assessment evaluation. The results showed the margin of error to be less than $5 \%$ which was consistent with the students' self-evaluation results. However, the same accuracy was not found in peer assessment marks from students. The results indicated that students tend to grade higher in peer evaluation which is consistent with Blom, Daniel and Searby $(1997 ; 2004$; 2004). The specific criteria grading sheet has been provided in appendix $2 b$. In this study the margin of variation was as high as $20 \%$. The reason for this level of variation could be because of peer pressure and peer evaluation was therefore only useful as a group exercise.

\section{Summative assessments}

The summative assessment results indicated that some students found the singing programme a challenge. Sophie, for example, commented "that it is too much in one go." Biggs and Tang (2007) stress the importance of assisting students in managing their time and effort. They recommended facilitators and educators should coordinate the timing of assessment tasks with assessment in other units to avoid a period of overload. The memo notes indicated that the students in this study believed they were stressed because of an overload of work. To help minimise this problem, students were given the opportunity to design an individualized timetable which enabled them to work through the skills test assessment at their pace and jurisdiction. This decision was aligned with Biggs and Tang (2007) recommendation that educators coordinate timetabling to ensure students timing of assessments are spread out over an appropriate timeline to avoid work overload.

Despite these efforts the summative results were disappointing for some of the students. These poor results could be attributed to the students' lack of application to the sport psychology based methods throughout the year. As 
mentioned earlier, Ericsson and Lehman (1996) considered the effects of deliberate practice engagement on performance achievement cannot be ignored; they state that, "As for expertise, the levels of performance individuals attain after years of experience alone are much lower than those who have adhered to regimens of careful training and practice" (p. 297).

\section{Summary, implications \& suggestions for future research}

The aim of this thesis was to examine the impact of a training programme based on sport psychology for a cohort of contemporary singing students. More specifically, it sought to reveal the participants' responses to engaging in aspects of sport psychology and the overall effect that the programme had on their performance achievement. The results showed that students did not embrace these initiatives and were generally reluctant to implement them.

Deliberate practice - No students were engaged in regular practice by the end of the academic year. Some students did work within the proposed deliberate practice framework with positive results. Their engagement proved to be spasmodic but the results showed that, when applied, the principles were effective. Another outcome relating to deliberate practice, which was highlighted in the literature, was the effect of a person's starting age. As this research has been conducted in a tertiary institution this matter needs further consideration. It is recommended that further research looks at adult learners and practice habit development.

Self-efficacy-The students' level of confidence was found to be affected by a range of factors. One of these was the students' level of preparedness for performance assessments. In a summative assessment it is desirable that students demonstrate their highest level of performance. However, in this 
programme students were required to form a band and rehearse with it within a relatively short period of time. At this level of study it cannot be assumed that all students are able to arrange a group of musicians. Some students are extremely confident in selecting musicians as they are in the 'in crowd'. However, if a student does not have the same level of popularity or favour with his/her peers it is likely to disadvantage them in their performance assessment. If the best musical environment is not provided for performance assessments, it is possible that these students are under achieving. Therefore, it is recommended that students have access to professional musicians, which would allow them to demonstrate their finest performance. It is also important that the students initiate a high standard of training, similar to periodization. In sport this sophisticated level of training ensures that individual's physical and psychological training are balanced and precise. This gives the athlete the optimum opportunity to reach their highest level of performance.

Motivational mechanisms - The majority of students favoured extrinsic motivational mechanisms which were deemed unfavourable in the sporting literature. This insight was valuable as it exposed the students' level of dependency in their learning. Although extrinsic motivators may not be seen as the most favourable means in performance achievement, this study found that they were necessary in encouraging intrinsic motivation. In the final focus group the findings did indicate that students were starting to show signs of self-regulatory learning (SRL). With a revised programme guided by positive educational practices for adult teaching it may be possible to improve the student (SRL) levels at an earlier stage of the programme. If students were better equipped by practice and (SRL) earlier in the programme, it is possible that they would exit the programme at a higher level of expertise. This would mean they would be better prepared for the music industry.

Goal setting - Students were focused on outcome goals, which are recognised in sport psychology as likely to cause negative performance outcomes. SMART goals were introduced by the vocal coach but was not 
adapted or used by the students. It was interesting to note that all students were focused on one aspect of their training and that was learning songs for an up-and-coming performance but not for the skill acquisition assessments. There was no point in the academic year where the upcoming performance was not the motivating factor for this group of students. The major focus was consistently their performance agenda. If they had applied the SMART framework for their goal setting this may have encouraged a physical and psychological training balance. It must be accepted that because students had not implemented appropriate goal setting a physical and psychological balance was never established, a fact which was reflected in the students' summative assessment results. Further investigation on the students' resistance to goal setting is necessary to reinforce progressive training processes.

Peak performance - the results showed that peak performance was sensed by students but their experience was identified rather as a state of 'flow'. Although students had "felt amazing" in a variety of performances throughout the academic year, they never showed signs of significant improvement. In fact, their overall performance and assessment results either stayed at the same level or in some cases declined. The aim of this study was to see if the introduction of sport psychology related teaching strategies would lead to a positive change in students' skill acquisition and performance achievement. The results showed that this did not happen. What was achieved was an in-depth examination of this vocal programme, which gave these students the opportunity to have voice on behalf of other contemporary singing students. The experience for the researcher was challenging and at time disappointing, but nevertheless was an amazing opportunity to re-think contemporary vocal pedagogy. With the knowledge gained from this investigation the researcher will re-evaluate the implementation of sport psychology methods and re-design the programme over a longer period of time. This could allow for both student and educator to develop and apply sport psychology more effectively. 
Sophie's statement "I just do it" was truly a reflection of these results and attitudes. The students' response to the sport psychology initiatives revealed that they were at a beginner's to intermediate level of study. On reflection, the programme designed was perhaps more suited to advanced learners and this may have been a contributory factor in the students' disengagement.

The degree to which the disengagement with these sport psychology based initiatives is related to the different context of singing rather than specifically to this particular group of students is difficult to ascertain. While there were glimpses of positive outcomes, when students implemented aspects of the programme, in general terms the degree of disengagement makes reaching firm conclusions difficult.

Students need, however, to be encouraged to take responsibility for their learning and as adults to understand the demands of the music industry. Without dedication and effort they will find it extremely difficult to cope or succeed in the professional music environment. The music industry is tough as Debbie Haywood stated (Chapman, 2010) - "life is tough out there for a musician. You slog it out - it is a myth that you just 'make it'. It takes enormous bottle and humility and talent to be a touring musician in a tiny country like New Zealand" (p.11).

In hindsight, the introduction of the sport psychology based initiatives needed to be introduced gradually throughout the vocal programme. Luke's statement 'too much at one time' would suggest that the students' previous expectations and personal ideas of practice inevitably disrupted the flow and direction of both student and vocal coach. There appeared to be too much information for the time allocated at this level of study. Therefore, it is recommended (1) contact time is increased which would allow for discussion and the development of course requirements, (2) the educational environment encourages autonomy, (3) that a regular forum is set up for students to voice their concerns and frustrations so that learning is not jeopardized, also (4) workshops with professionals on study/learning habits and finally (5) changes 
to facilities for practice. If these issues are not addressed the relationship between the vocal coach/student could diminish confidence and interfere with both parties' performance achievements.

\section{Limitations}

This study had a number of limitations. Firstly, it involved a relatively small number of students from one tertiary institution in New Zealand. This small number when aligned with the selected methodology means that there can be no attempt to generalise the results to other contexts. The dual role of teacher and researcher can be considered as a limitation which led to a necessary distancing of the researcher from the data collection. The idea of applying sports psychology to singing teaching, however, has transferability to other applied teaching contexts.

\section{Final Statement}

The celebration of this researcher was being part of a research project that gave voice to the contemporary singer. The opportunity to examine the impact of sport psychology on a cohort of contemporary singers has in a small way added to the body of knowledge in singing pedagogy. Of course, further research is needed in the area of practice application and the balance of physical and psychological training in this genre. It would also be worthwhile to research professional contemporary singers' practice behaviours. I encourage contemporary vocal educators to re-evaluate their processes and to promote the highest standard of professional practice which will enable contemporary singers to reach their full potential. 


\section{References}

Agassi, A. (2009). Open. London: HarperCollins Publishers.

Andersen, M. B. (2000). Doing sport psychology. Australia: Human Kinetics.

Anderson, L., \& Krathwohl, D. (2001). Taxonomy for learning, teaching and assessing: A Revision of Bloom's Taxonomy of Education Objectives. NY: Longman.

Arai, S. M. (1997). Empowerment: from the theoretical to the personal. In L. Kidman (Ed.), Developing decision makers (pp. 16-17). Journal of Leisurability, 24(1), 3-11.

Bandura, A. (1977). Self-efficacy: Toward a unifying theory of behavioural change. Psychological Review, 84, 191-215.

Bandura, A. (1997). The exercise of control. New York: Freeman.

Becker, A. J., \& Wrisberg, C. A. (2008). Effective coaching in action: observations of legendary collegiate basketball coach Pat Summitt. The Sport Psychologist, 22, 197-211.

Beltman, S. (2005). Motivation of high-achieving athletes and musicians: a person-context perspective. Unpublished Phd, Murdoch University, Murdoch, Australia. 
Biggs, J., \& Tang, C. (2007). Teaching for quality learning at university. New York: McGrawHill.

Blom, D., \& Poole, K. (2004). Peer assessment of tertiary music performance: Opportunities for understanding performance assessment and performing through experience and self-reflection. British Journal of Music Education, 21(1), 111-125.

Bloom, B. S. (1985). Developing talent in young people. New York: Ballantine.

Bong, M., \& Clark, R. (1999). Comparison between self-concept and selfefficacy in academic motivation research. Educational Psychologist, 34(3), 139-153.

Bonnevill-Roussy, A., Lavinge L. L. \& Vallerand, R. J. (2010). When passion leads to excellence: the case of musicians. Psychology of Music, 39(1), 123-138.

Burt-Perkins, R., \& Mills, J. (2008). The role of chamber music in learning to perform: a case study. Music Performance Research, 2, 26-35.

Carron, A. V. (1982). Cohesiveness in sport groups: Interpretations and considerations. Journal of Sport Psychology, 4, 123-138.

Carron, A. V., Brawley, L., \& Widmeyer, W. N. (2002). The Groups Environment Questionaire: Test Manual. Morgantown, West Virginia: Fitness Information Technology, Inc. 
Chapman, I. (2010). Kiwi rock chicks, pop stars \& trailblazers. Auckland: HarperCollins Publishers.

Colvin, G. (2008). Talent is overrated. New York: Penguin Group.

Cosma, J. B. (1999). Flow in teams. Dissertation Abstracts International Section A. In E. Mosek (Ed.) An exploration of team flow in an Israeli youth basketball competitive team. Humanities and Social Sciences, 60(6-A).

Crotty, M. (1998). The foundations of social research. Australia: Allen \& Unwin Pty Ltd.

Csikszentmihalyi, M., Rathunde, K. and Whalne, S. (1993). Talented teenagers: The roots of success and failure. Cambridge: Cambridge University Press.

Cskiszentmihalyi, M. (1975). Beyond boredom and anxiety: The experience of play in work and games. San Fransicso: Jossey-Bass.

Daniel, R. (2004). Peer assessment in musicial performance: the development, trial and evaluation of a methodology for the Australian tertiary environment. British Journal of Music Education,, 21(1), 89-110.

Davis, R., \& Pulman, M. (2001). Raising standards in performance. British Journal of Music Education,, 18(3), 251-259. 
Deci, E. L., \& Ryan, R. M. (2008). Facilitating Optimal Motivation and Psychological Well-Being Across Life's Domain. Honorary President's Address, Canadian Psychology, 49(1), 14-23.

Denscombe, M. (2003). The good research guide: for small-scale social research projects. Philadelphia: Open University Press.

Denscombe, M. (2010). The good research guide: for small-scale social research projects. New York: Open University Press.

Denzin, N., and Lincoln, Y. (Eds.) (2008). Introduction: The discipline and practice of qualitative research. (3rd ed.). California: Sage.

DeVenzio, D. (1997). Think like a champion. Charlottek, North Carolina: The Fool Court Press.

Durand-Bush, N., Salmela, J. H. \& Green-Demers, I. (2001). The Ottawa Mental Skills Assessment Tool (OMSAT-3). The Sport Psychologist, 15, 1-19.

Ericsson, K., \& Lehmann A. (1996). Expert and Exceptional Performance: Evidence of Maximal Adaptation to Task Constraints. Annual Review of Psychology, 47, 273-305.

Ericsson, K. A. (2006). The Influence of Experience and Deliberate Practice on the Development of Superior Expert Performance. The Cambridge Handook of Expertise and Expert Performance, 685 - 707 
Ericsson, K. A., Krampe, Ralf Th., and Tesch-Romer (1993). The role of deliberate practice in the acquisition of expert performance. Psychological Review, 100(3), 363-406.

Gill, D. L. (2000). Psychological dynamics of sport and exercise. Champaign, IL: Human Kenetics.

Greene, D., Ph.D (2001). Audition success: An olympic sports psychologists teaches performing artists how to win. New York: Routledge.

Hamilton, L. (2007). My story. London: HarperSport.

Hodge, K. (2004). Sport motivation: Training your mind for peak performance. Auckland: Reed Publishing (NZ) Ltd

Hodge, K. (2005). The complete guide to sport motivation. London: A \& C Black.

Holliday, B., Burton, D., Greg, S., Hammermeister, J., Naylor, S., \& Freigang, D. (2008). Building the Better Mental Training Mousetrap: Is Periodization a More Systematic Approach to Promoting Performance Excellence? Journal of Applied Sport Psychology, 20(2), 199-219.

Horn, T. S. (2008). Advances in sport psychology (Third ed.). United States of America: Human Kinetics Inc. 
Howe, M. J. A., Davidson, J. W., \& Sloboda, J. A. (1998). Innate talents: myth. Behavioral and Brain Science, 21, 399-407.

Jackson, S. A. (1992). Athletes in flow: A qualitative investigation of flow states in elite figure skaters. Journal of Applied Sport Psychology, $4(161-180)$.

Jackson, S. A., \& Csikszentmihalyi, M. (1999). Flow in sports: The keys to optimal experiences and performance. Champaign, Illinois: Human Kinetics.

Johnson, R. B., \& Christensen, L. B. (2008). Educational Research: Quantitative, Qualitative, and Mixed Approaches. Los Angeles, California: Sage Publications, Inc.

Jordan, M. (1998). For the love of the game. New York: Crown.

Jorgensen, H. (2002). Instrumental performance expertise and amount of practice among instrumental students in a conservatoire. Music Education Research., 4(1), 105-119.

Kidman, L. (2001). Developing decision makers. Christchurch: Innovative Print Communications Ltd.

Kidman, L., \& Hanrahan, S. (2004). The coaching process: A practical guide to improve your effectiveness. New Zealand: Dunmore Press Limited. 
Kipp, L., \& Amorose, A. (2008). Perceived Motivational Climate and SelfDetermined Motivation in Female High School Athletes. Journal of Sport Behavior, 31(2).

Kirschenbaum, D. (1997). Mind matters: Seven steps to smarter sport performance. Carmel, IN: Cooper.

Kornspan, A. S. (2009). Fundamentals of sport and exercise psychology. United States of America: Human Kinetics.

Kostka, M. J. (2002). Practice Expectations and Attitudes: A Survey of College-Level Music Teachers and Students. Journal of Research in Music Education, 50(2), 145-154.

Krause, K. B., Duchesne, S., \& McMaugh, S. (2010). Educational psychology for learning \& teaching. Australia: Cengage learning Australia Ply Limited.

Lacaille, N., Whipple, N., \& Koestner, R. (2005). Reevaluating the benefits of performance goals: The relation of goal type to optimal performance for musicians and athletes. Medical Problems of Performing Artists, 20(1), 11-16.

Latukefu, L. (2010). Peer assessment in tertiary level singing: Changing and shaping culture through social interaction. Research Studies in Music Education, 32(1), 61-73. 
Lebler, D. (2006). 3D assessment: looking through a learning lens. Paper presented at the at the New models for educating professional musicians in the twenty-first century: proceedings of the 16th International Seminar of the Commission for the Education of the Professional Musician (CEPROM), Hanoi, National Conservatory of Music.

Lebler, D. (2008a). Perspective on assessment in the learning of music. In D. Bennett \& M. Hannan (Eds.), Inside, Outside, Downside Up: Conservatorie Training and Musicians' Work. Perth: Black Swan Press.

Lebon, R. L. (2006). The versatile vocalist: Singing Authentically in Contrasting Styles and Idioms. USA: Scarecrow Press, Inc.

Lehman, A. C. G., H. (2006). Music. In K. A. Ericsson, N. Charness, P. J. Feltovich \& R. R. Hoffman (Eds). New York: Cambridge University Press.

Lehmann, A. \& Davidson, J. (2002). Scientific Approach to Practice: Deliberate (Formal) Practice. In R. Colwell, \& C. Richardson (Eds.), The New Handbook of Research on Music Teaching and Learning. New York: Oxford Univeristy Press.

Lehmann, A. \& Davidson, J. (2006). Taking an acquired skills perspective on music performance. In R. Colwell (Ed.), MENC Handbook of musical cognition and development. New York: Oxford University Press.

Leith, L., M. (2008). The psychology of achieving sports excellence. Toronto: Sports Book Publisher. 
Loehr, J. E. (1984). How to Overcome Stress and Play at Your Peak All the Time. Tennis (March), 66 - 76.

Lynch, J. (2001). Creative coaching. United States of America: Human Kinetics.

Mageau, M. A., Vallerand, R. J., Charest, J., S, S., N, L., Bouffard, T., et al. (2009). On the development of harmonious and obsessive passion: The role of autonomy support, activity specialization, and identification with the activity. Journal of Personality and Social Psychology, 77(3).

Marchant, D. B. (2000). Targeting futures: Goal Setting for Professional Sports. In Mark B. Andersen (Ed.), Doing Sport Psychology (pp. 93103). United States of America: Human Kinetics.

Marsh, H. W. (1984a). Self-concept: The application of a frame of reference model to explain paradoxical results. Australian Journal of Education, $28,165-181$.

Marsh, H. W. (1984b). Self-concept, social comparison, and ability grouping: A reply to Kulik and Kulik. American Educational Research Journal 21, 799-806.

Marsh, H. W., \& Peart N. D. (1988). Competitive and cooperative physicial fitness training for girls: Effects on physicial fitness and multidimensional self-concepts. Journal of Sports and Exercise Psychology, 10, 390-406. 
Martin, J. J., \& Culter, K. (2002). An Exploratory Study of Flow and Motivation in Theater Actors. Journal of Applied Sport Psychology, 14(4), 344352.

Maslow, A. (1968). Toward a psychology of being. New York: Van Nostrand.

Mclnerney D. M. \& Mclnerney, V. (2006). Educational psychology constructive learning. Australia: Pearson Australia Group Pty Ltd.

Merriam, S. (1998). Qualitative research and case study applications in education. California: Jossey-Bass.

Merriam, S. (2009). Qualitative research: A Guide to Design and Implementation. San Francisco: Jossey-Bass.

Mills, J. (1991). Assessing musical performance musically. Educational Studies, 17(2), 173-181.

Moore, B. (2010). Playing Your Best When It Counts. American Music Teacher, 61(6), 186.

Moreno, J. A., Gonzalez-Cutre, D., Martin-Albo, J., \& Cervello, E. (2010). Motivation and performance in physical education: An experimental test. Journal of Sports Science and Medicine, 9, 79-85. 
Moritz, S., Feltz, D., Fahrback, K., \& Marck, D. (2000). The relation of selfefficacy measures of sport performance: a meta-analytic review. Research Quarterly for Exercise \& Sport, 71(3), 280-294.

Mosek, E. (2009). An exploration of team flow in an Israeli youth basketball competitive team. Univeristy of Jyvaskyla, Israel.

Murray, H. A. (1938). Exploration in personality. New York: Oxford University Press.

Navin, A. (2011). Sports coaching: A reference guide for students, coaches and competitors. Ramsbury: The Crowood Press Ltd.

Navin, A., \& Egan, D. (2011). Management of participants behaviour. In A. Navin (Ed.), Sports coaching: Reference Guide for Students, Coaches and Competitors. Ramsbury: The Crowood Press Ltd.

Nielsen, S. (2001). Self-regulating Learning Strategies in Instrumental Music Practice Music Education Research., 3(2), 155-167.

Nielsen, S. (2008). Achievement goals, learning strategies and instrumental performance. Music Education Research., 10(2), 235-247.

Orlick, T., \& Partington, J. (1988). Mental links to excellence. Sport Psyhologist, 2, 105-130. 
Peckham, A. (2000). The Contemporary Singer: Elements of Vocal Technique. Boston: Berklee Press.

Privette, G. (1983). Peak experience, peak performance and flow: A comparative analysis of positive human experience. Journal of Personality and Social Psychology 45, 1361-1368.

Ravizza, K. (1984). Qualities of the peak experience in sport. In Psychological Foundation of Sport. Champaign, IL: Human Kinetics.

Ravizza, K. (1990). Sportpsych consultation issues in professional baseball. The Sport Psychologist, 4, 330-340.

Salmela, J. H. (1996). Great job coach: Getting the edge from proven winners. Ottawa, Canada: Potentium.

Saunders, T., \& Holahan, J. (1997). Criteria-specific rating scales in the evaluation of high school instrumental performance. Journal of Research in Music Education, 45(2), 259-272.

Searby, M., \& Ewers, T. (1997). An evaluation of the use of peer assessment in higher education: A case study in the school of music, Kingston Univeristy. Assessment \& Evaluation in Higher Education, 22(4), 371383.

Shepherd, J. (2006). The complete guide to sport training. London: A \& C Black. 
Sluijsmans, D. M., \& Prins, F. (2006). A conceptual framework for integrating peer assessment in teacher education. Studies of Education Evaluation, 32, 6-22.

Stake, R., E. (1995). The art of case study research. California: Sage Publications, Inc.

Stanely, M., Brooker, R., \& Gilbert, R. (2002). Examiner Perceptions of Using Criteria in Music Performance Assessment Research Studies in Music Education, 18(46), 46-56.

Thorne, F. (1963). The clinical use of nadir experience reports. Jounral of Clinical Psychology, 19, 248-250.

Tuckman, B. W. (1965). Developmental sequence in small groups. Psychological Bulletin, 63, 384-399.

Tuckman, B. W., \& Jensen, M. A. C., (1977). Stages of small group developmeent revisited. Group and organizational studies, 2(419-427).

Vallerand, R. J., \& Houlfort, N. (2003). Passion at work: Toward a new conceptualization. . In D. Skarlicki, S. Gilliland, \& D. Steiner (Eds), Research in Social Issues in Management, 3, 175-204.

Wrigley, W. J. (2005). Improving Music Performance Assessment. Unpublished Phd, Griffith University, Brisbane. 
Yin, R. (2009). Case study research: Design and Methods (fourth ed. Vol. 5). California: Sage Inc. 


\section{Appendices}

Appendix 1: Information and consent form

An examination of the impact of a training programme based on sport psychology for a cohort of contemporary singing students STUDENT INFORMATION SHEET

1. Researcher Details

Sandy Cairns-James

54 Brooker Grove, Newlands, Wellington 6039

Tel. 044774557 or 0274607322

sacj@xtra.co.nz

Sandy.Cairns-James@whitireia.ac.nz

\section{Supervisors}

Dr Barrie Gordon

barrie.gordon@vuw.ac.nz

Tel. 044639770

Jenny Wollerman

jenny.wollerman@nzsm.ac.nz

Tel. 044639730

\section{Assisting Colleague}

Dr Alison Viskovic

Alison.viskovic@whitireia.ac.nz

Tel. 237 3103, ext 3768

2. Outline of Research Project 120 
I am undertaking research that will provide valuable information on training tertiary level contemporary singing students using methods developed by sport psychology.

My aim is to investigate features of sport psychology, both physical and psychological, that can be used to train a contemporary singer for peak performance. The information collected will assist in the area of curriculum development for singing students.

\section{Participants' involvement}

You are invited to:

- Take part in two focus groups during the year (mid-year and end-of-year) which would each take approximately one hour, and be audio taped. These will be conducted by Alison Viskovic. You will have the right at any time in the focus group to leave or request that what you have said not be written into the final transcript.

- Agree to Sandy reviewing your mid-year and end-of-year performance assessment videotapes after all grades have been reported.

- Hand in your workbooks at the end of the year 2011 for Sandy to review, (after all grades have been reported) for research rather than teaching purposes.

\section{Confidentiality}

If you agree to participate, your name will not be given to Sandy until all final assessments have been marked and reported. That means she will not know during the year who is a participant or non-participant, and so her teaching and grading of you cannot be affected.

Participants will be known to the researcher and assisting colleague, but will not be named or identifiable in the final reporting. 
Audio tapes of focus groups will be transcribed under conditions of confidentiality. Workbooks reviewed at the end of year will be confidential to Sandy and the supervisors.

When the project is completed the data will be held securely for 5 years. After that time the material will be destroyed, except for performance videotapes which will be returned to the Faculty archives.

\section{Participants' rights}

Under the protocols used by Victoria University's Human Ethics Committee, participants have the right to:

- Decline participation

- Withdraw from the project at any time

- Refuse to answer any question

- Ask any questions about the project at any time during participation

- Provide information on the understanding that their names will not be used

- Be given a brief summary of the research when it is finished. If you wish to receive a summary please indicate on the consent form

If you have any questions or queries during this research project please do not hesitate to contact the primary supervisor at anytime:

Dr Barrie Gordon

Senior Lecturer, School of Education Policy and Implementation,

Victoria University of Wellington, PO Box 600, Wellington, 6140.

Email: barrie.gordon@vuw.ac.nz

Tel. 044639770 
You may also contact Alison Viskovic in the Whitireia Faculty of Arts if you have queries about the focus groups or use of Whitireia data.

Alison.viskovic@whitireia.ac.nz

Tel. 237 3103, ext 3768

6. Consent

Participants will be asked to give their consent in writing before taking part in this research.

\section{Results}

Publication of results in the project will be reported in a Master of Arts thesis and will be held in the Victory University Wellington library. This research may also be reported in academic journals or at conferences.

\section{STUDENT CONSENT FORM}

An examination of the impact of a training programme based on sport psychology for a cohort of contemporary singing students

Researcher Sandy Cairns-James

1. I have read the Information sheet and have had the details of the study explained to me. My questions have been answered to my satisfaction, and I understand I may ask further questions at any time.

2. I agree to digital recordings of my 2011 performance assessments being viewed by Sandy Cairns-James at the end of 2011 for this project. 
3. I agree to my 2011 singing workbooks being reviewed by Sandy Cairns-James at the end of 2011 for this project.

4. I agreed to take part in two focus groups in 2011 , which will be audio recorded and transcribed by Alison Viskovic for the purpose of this project.

5. I understand I can withdraw during the project, but data collected before that time cannot be withdrawn. (Withdrawal to be notified to A. Viskovic)

6. I understand that if I choose to participate in this study that my participation or non-participation will be unknown to Sandy Cairns-James until all 2011 assessments have been marked and reported, so that my participation or non-participation will not affect my studies or assessments in any way.

Signed:

Name:

Date: 
Appendix 2a: focus group one (FG1)

1. Have you noticed changes in Sandy's approach from Level 4 to Level 5 this year?

2. Did these changes work for you, and if so, what was their impact? If not, why do you think it didn't work for you?

3. Did the workbooks work for you? Did they help your deliberate practice?

4. Did you understand the aims of the exercise and the sport psychology ideas in the workbooks?

5. Can you describe your best performance/performance this year? What did that feel like?

6. Did you get a sense of peak performance in any performance or assessment this year and if so, what did that feel like?

7. Do you feel at this stage of your singing development that it is possible to experience peak performance?

8. If you have not experienced peak performance is there anything that you feel may hinder you from doing so?

9. Self and peer evaluation were encouraged during your group sessions - did you find these useful, and if so in what ways?

10. Did anything new that Sandy tried this year get in the way of your learning, if so what and how? 
11. Did anything new that Sandy tried this year particularly help you, if so could you explain?

12. Compared with the beginning of this year, what is different in the way you would now prepare for a major performance?

13. The questions were used first at mid-year, and repeated at end-of year with modifications, if indicated as needed by feedback during the year.

\section{Appendix 2b: Focus Group Questions (FG2)}

(Brackets for likely follow-up questions)

1. Tell me about your patterns of practice (did the workbooks help?)

2. As the year has gone on, how have the workbooks impacted on your training?

3. How did your preparation for the schools tour compare with your preparation for a performance assessment?

4. Rehearsing with a band is a form of practice - how is that different for you from practising on your own (did Sandy's suggestions help?)

5. Thinking about the school tour performances, how were they like or unlike singing for assessments?

6. Describe your personal best performance so far this year - what, when, where? Did it give you a sense of peak performance? (If you have not yet experienced a peak performance, is there something you feel is hindering you?)

7. Performing in a band, how it works as a team can produce or hinder peak performance - what has been your experience so far this year?

8. What motivates you or encourages you to practice and perform well? (What decreases motivation for you?) 
9. What are you looking forward to continuing or building on next year?

10. Sandy has based some of her methods this year on the ways sports people are trained, but for them there is also an element of competition - do you think a lack of direct competition in the music context makes much difference - if so, how?

11. Compared with the end of last year, what is different in the way you would now prepare for a major performance?

12. Self and peer evaluation were encouraged during your group sessions - did you find these useful, and if so in what ways?

13. Have you any other comments or suggestions for Sandy (relating to deliberate practice, peak performance, motivation,

Used at mid-year:

1. What are the main changes you noticed in Sandy's approach from Level 4 to Level 5 this year?

2. How did these changes work for you and what was their impact?

3. How well did the workbooks work for you? Did they help your deliberate practice?

4. Did you get a sense of peak performance in any performance or assessment this year and if so, what did that feel like?

5. Self and peer evaluation were encouraged during your group sessions - did you find these useful, and if so in what ways?

6. Did anything new that Sandy tried this year get in the way of your learning, if so what and how?

7. Did anything new that Sandy tried this year particularly help you, if so could you explain? 
8. Compared with the beginning of this year, what is different in the way you would now prepare for a major performance?

\section{Appendix 2a: Question for assessor and moderator}

Was there any noticeable differences between the level of performance from last year level 5 students and this year level 5 students? It so, what did you notice?

Was there evidence of improved student preparation for performance assessments? If so, what? If not, could you explain?

Could you identify an apparent state of 'flow' in a student?

This year we have used a revised grading sheet with more focus on the vocal features to be assessed (and gave copies beforehand to the students) Did this sheet help you to identify vocal factors and performance factors?

My approach this year is based on using sport psychology to develop peak performance - have you any comments based on your own experience of such approaches?

Have you other suggestions that would help to prepare singing students for peak performance on major occasion 
Appendix 2b: Criteria Grading Sheet

Student: Date:

Assessor:

Please grade each criteria from $1-10-$ poor $=1$ and excellent $=10$

\begin{tabular}{|c|l|l|l|l|}
\hline Criteria & song 1 & song 2 & song 3 & Song 4 \\
\hline 1. Vocal and breath control & & & & \\
\hline 2. Rhythm/timing & & & & \\
\hline 3. Pitch & & & & \\
\hline 4. Diction/articulation & & & & \\
\hline 5. Projection \& dynamic control & & & & \\
\hline 6. Tone variation (Timbre/vocal quality) & & & & \\
\hline 7. Expressive \& Interpretation & & & & \\
\hline 8. Memorization & & & & \\
\hline 9. Stage crafting (presentation) & & & & \\
\hline 10. Audience communication & & & & \\
\hline
\end{tabular}

\section{Comments}


Appendix 3: GPSMAD - memoing technique

\begin{tabular}{|l|}
\hline Name: \\
\hline (G)oals: \\
\hline (P)erformance: \\
\hline (S)elf-efficacy: \\
\hline (M)otivation: \\
\hline (A)ssessment: \\
\hline (D)eliberate practice: \\
\hline Other: \\
\hline Comments: \\
\hline
\end{tabular}


Appendix 4a - Sample layout of Book one (week one)

\section{What is Deliberate Practice?}

Deliberate practice is a term that has originated from K. Ericsson. Ericsson asked why some people practise but do not seem to gain expertise in their ability. In other words the person's ability in a skill seems to stand still or even decline in the skill they are practicing. This may be because they have reached a 'plateau' and need to stay at the same level of training before they move on.

In sport psychology deliberate practice (DP) is common. Athletes know they need to work hard and deliberately and regularly if they want to improve their skills. People with talent still need to practise to keep improving.

\section{How does DP Work?}

Deliberate practice works when a training process is deliberately designed with purpose. This allows the person to practise and understand why they are doing what they are doing and what they should gain from the designed programme.

\section{Is practising not all equal?}

All practice is not equal. If you practise something repeatedly doing the same thing over and over again, yet do not improve, the practice is likely to be developing bad habits rather than positive skill acquisition. The old saying "practice makes perfect" is not necessarily true if you are practicing incorrectly.

\section{How can I practice and foster DP?}

Firstly, design a personalized programme with your vocal tutor that develops the strengths and improves the weak areas in your voice. Keep a daily vocal training diary, which allows you to watch your progress. It is also important to set short and long term achievable goals to develop DP skills. Each week discuss your successes and challenges with your vocal coach and make necessary changes 


\section{Deliberate Practice}

\section{Week One - Daily Practice}

Technique

BODY WARM-UP

5 minutes daily - actual time

Focus on Alignment
Day
Time
Comments

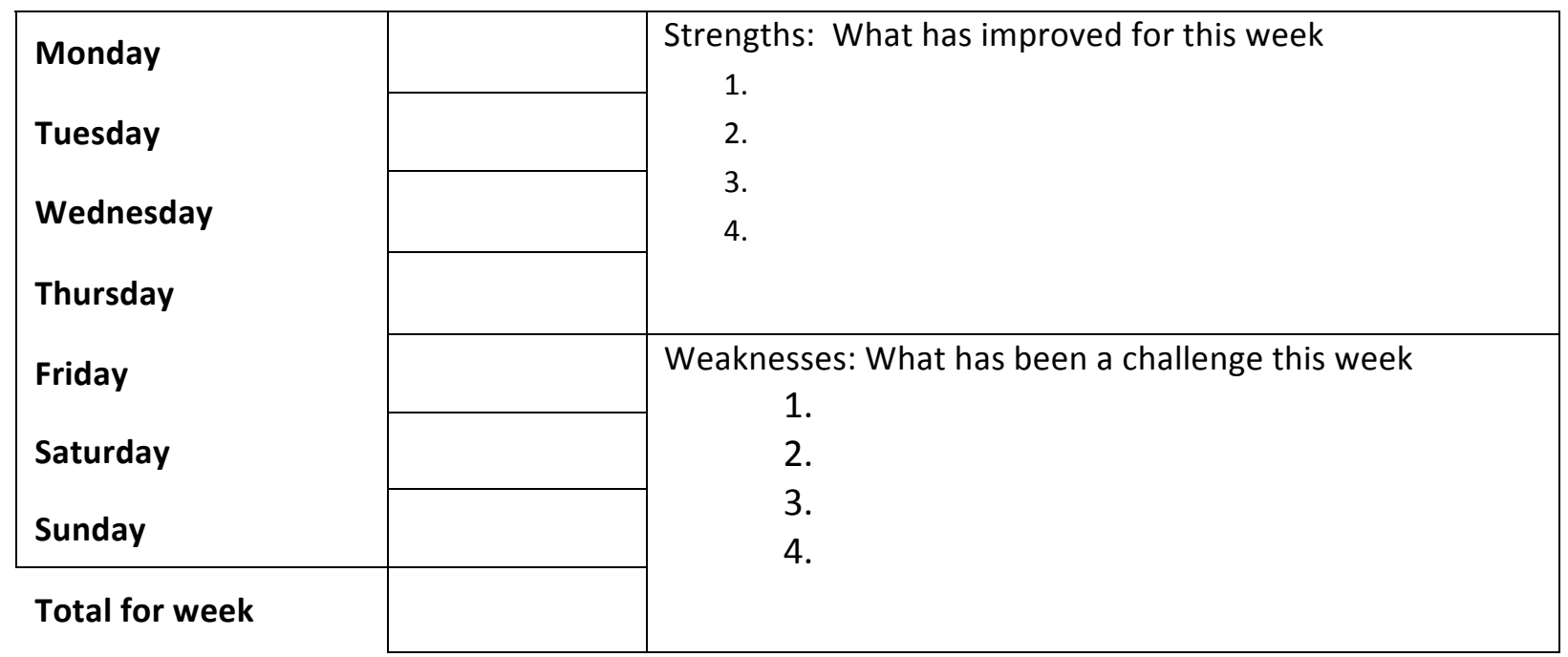

BREATHING EXERCISES

5 - 10 minutes daily - actual time

1. Floor exercise

2. Waistband exercise

Day

Time

Comments

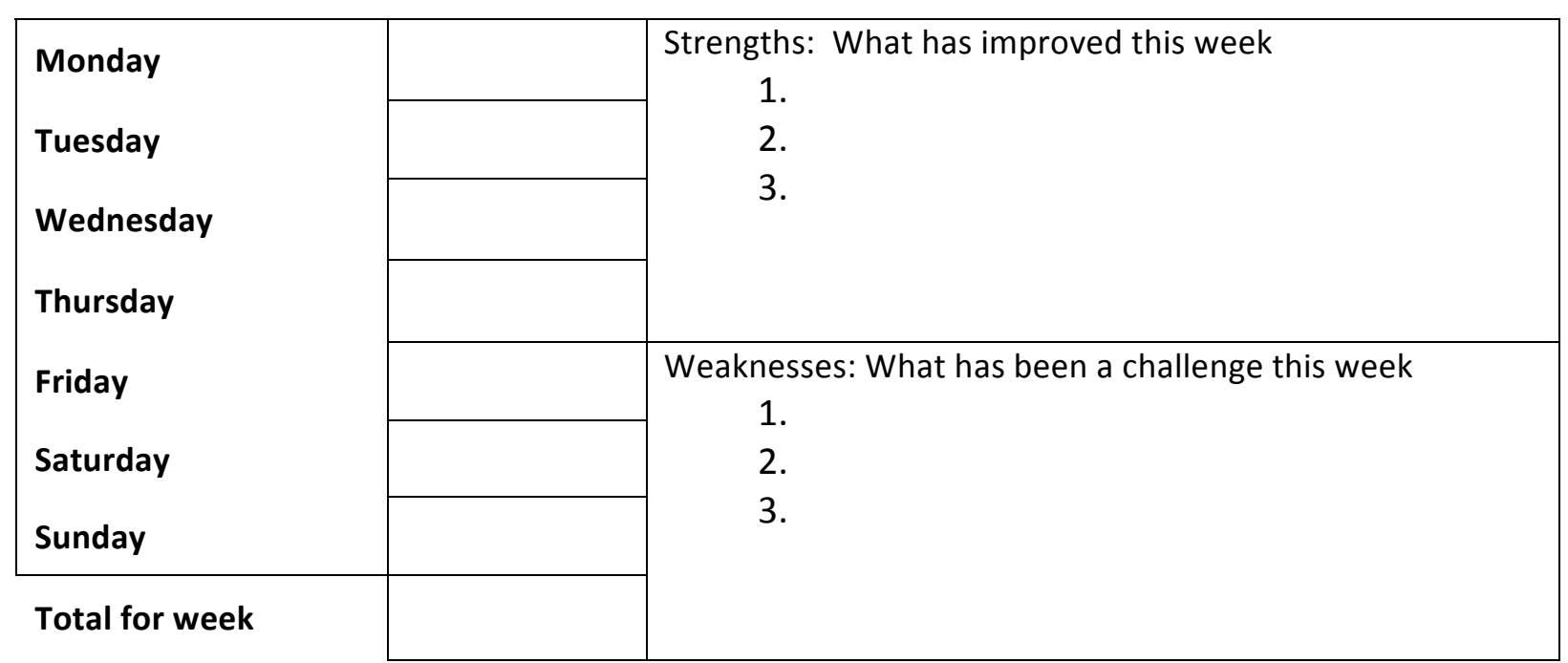




$\begin{array}{ll}1 & \text { Jazz - tracks - Dorian } \\ 2 & \text { Individual exercises }\end{array}$

1.

2.

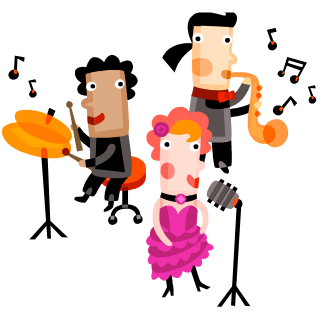

Day Time Comments

\begin{tabular}{|c|c|}
\hline Monday & \multirow{4}{*}{$\begin{array}{l}\text { Strengths: What has improved this week } \\
1 . \\
2 . \\
3 . \\
4 .\end{array}$} \\
\hline Tuesday & \\
\hline Wednesday & \\
\hline Thursday & \\
\hline Friday & \multirow{4}{*}{$\begin{array}{l}\text { Weaknesses: challenges this week } \\
1 . \\
2 . \\
3 . \\
4 .\end{array}$} \\
\hline Saturday & \\
\hline Sunday & \\
\hline Total & \\
\hline
\end{tabular}

MUSICIANSHIP

15 minutes daily - actual time

1 Scales: Major

2 Scales Minor (Dorian)

3 Pentatonic - major and minor

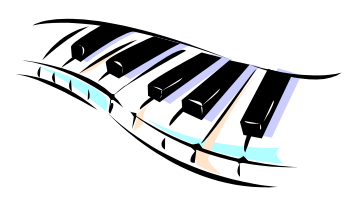

$4 \quad$ Intervals - ascending and descending including the $9^{\text {th }}$

Day Time Comments

\begin{tabular}{|c|c|}
\hline Monday & $\begin{array}{l}\text { Strengths: What has improved this week } \\
1 .\end{array}$ \\
\hline Tuesday & $\begin{array}{l}2 . \\
3\end{array}$ \\
\hline Wednesday & 4. \\
\hline Thursday & \\
\hline Friday & $\begin{array}{l}\text { Weaknesses: challenges this week } \\
1 .\end{array}$ \\
\hline Saturday & 2. \\
\hline Sunday & 4. \\
\hline
\end{tabular}


TRANSCRIPTION 15 minutes daily - actual time

Groove Blues - written transcription and scat
Day
Time
Comments

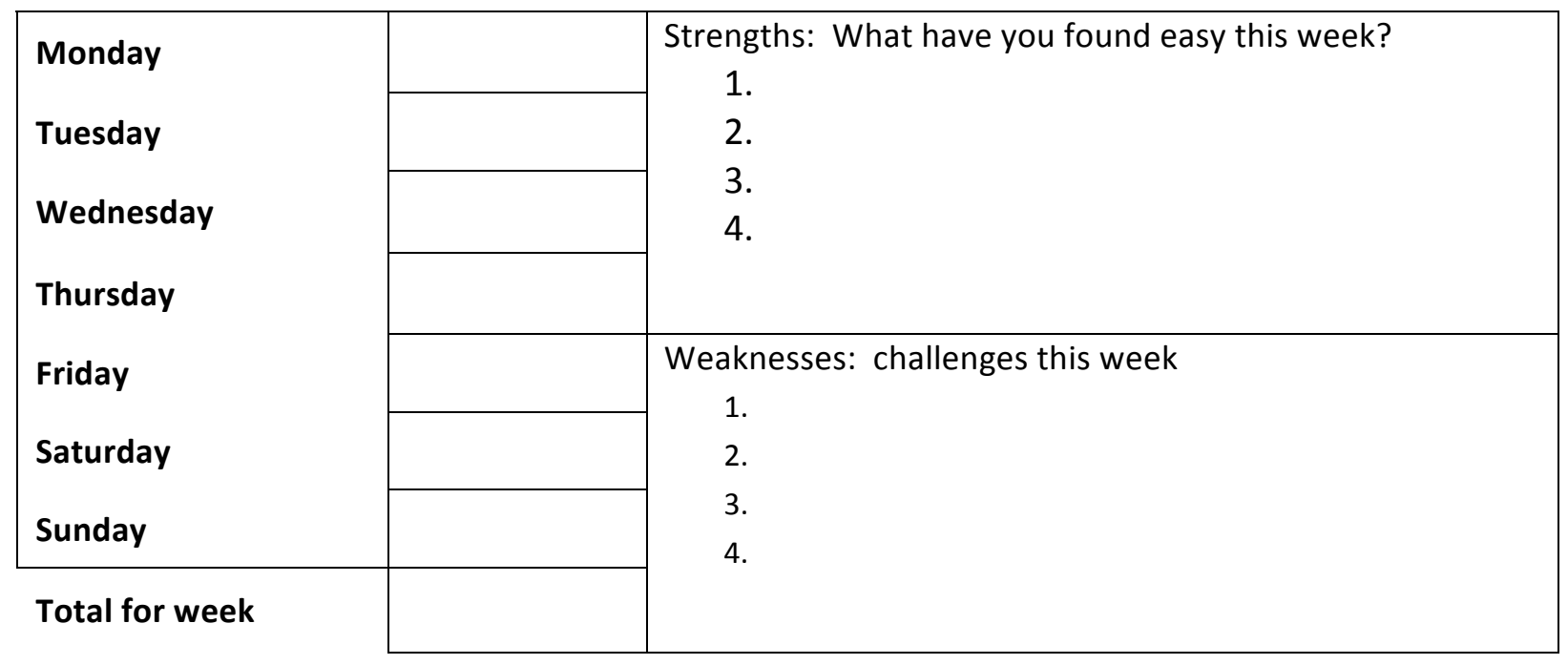

Performance

30 minutes daily - actual time

Song Preparation

3 songs

Ballad

Favourite performance song

Focus on breathing

Fast song

Focus on emotion/expressive skills

Focus on agility and diction

Day Time Comments

\begin{tabular}{|c|c|}
\hline Monday & \multirow{4}{*}{$\begin{array}{l}\text { Strengths: Improvements in your performance training } \\
1 . \\
2 .\end{array}$} \\
\hline Tuesday & \\
\hline Wednesday & \\
\hline Thursday & \\
\hline Friday & \multirow{4}{*}{$\begin{array}{l}\text { Weaknesses: Did you practise every day - if not, why not? } \\
\text { What factors influenced your availability to practice? } \\
1 . \\
2 . \\
3 . \\
4 .\end{array}$} \\
\hline Saturday & \\
\hline Sunday & \\
\hline Total for week & \\
\hline
\end{tabular}


Watch DVD of favourite artist

What could be useful to your own performance?

Goal setting

short and long term goals

\section{Comments}


Appendix 4b: an example from students deliberate practice workbook

\section{Technique}

Strengths

Flexibility improving

Weaknesses

finding my diaphragm

Don't know waistband exercise

\section{Musicianship}

Strengths

memorizing the lyrics to my songs

Weakness

ear-training and theory stuff

Running out of time starting to stress about skills test - Damn!!!

\section{Motivation}

My favourite artist is generally band oriented: play an instrument or is part of a collective group of musicians. 